A Global Set of Subduction Zone Earthquake Scenarios and Recurrence Intervals Inferred From Geodetically Constrained Block Models of Interseismic Coupling Distributions

Shannon E. Graham

Department of Physics

The College of New Jersey, Ewing, NJ USA

shannonegraham@gmail.com

John P. Loveless

Department of Geosciences

Smith College, Northampton, MA USA

jloveles@smith.edu

Brendan J. Meade

Department of Earth and Planetary Sciences

Harvard University, Cambridge, MA USA

meade@fas.harvard.edu

This is a non-peer reviewed preprint submitted to EarthArXiv. The manuscript has been submitted to $G^{3}$. 


\title{
A Global Set of Subduction Zone Earthquake Scenarios and Recurrence Intervals Inferred From Geodetically Constrained Block Models of Interseismic Coupling Distributions
}

\author{
Shannon E. Graham ${ }^{1}$, John P. Loveless ${ }^{2}$, Brendan J. Meade ${ }^{3}$ \\ ${ }^{1}$ Department of Physics, The College of New Jersey, Ewing, NJ USA \\ ${ }^{2}$ Department of Geosciences, Smith College, Northampton, MA USA \\ ${ }^{3}$ Department of Earth and Planetary Sciences, Harvard University, Cambridge, MA USA \\ (Depar
}

\section{Key Points:}

- We estimate and relate interseismic coupling areas on global subduction zones to potential earthquake magnitudes.

- We use estimated slip deficit rates to define recurrence intervals for potential earthquakes.

- Globally, regions of 50 percent coupling are consistent with 6 magnitude 9 or greater earthquakes.

Corresponding author: Shannon Graham, grahams@tcnj.edu 


\section{Abstract}

The past 100 years have seen the occurrence of five $\mathrm{M}_{\mathrm{W}} \geq 9$ earthquakes and $94 \mathrm{M}_{\mathrm{W}} \geq$ 8 earthquakes. Here we assess the potential for future great earthquakes using inferences of interseismic subduction zone coupling from a global block model incorporating both tectonic plate motions and earthquake cycle effects. Interseismic earthquake cycle effects are represented using a first-order quasistatic elastic approximation and include $\sim 10^{7}$ $\mathrm{km}^{2}$ of interacting fault system area across the globe. We use estimated spatial variations in decadal-duration coupling at 15 subduction zones and the Himalayan range front to estimate the locations and magnitudes of potential seismic events using empirical scaling relationships relating rupture area to moment magnitude. As threshold coupling values increase, estimates of potential earthquake magnitudes decrease, but the total number of large earthquakes varies non-monotonically. These rupture scenarios include as many as 14 recent or potential $\mathrm{M}_{\mathrm{W}} \geq 9$ earthquakes globally and up to 18 distinct $\mathrm{M}_{\mathrm{W}} \geq$ 7 events associated with a single subduction zone (South America). We also combine estimated slip deficit rates and potential event magnitudes to calculate recurrence intervals for large earthquake scenarios, finding that almost all potential earthquakes have a recurrence time of less than 1,000 years.

\section{Plain-language summary}

Earthquake forecasting is a fundamental goal of earth science. Forecasts are often based on patterns of past earthquakes in space and time but can be augmented with information from global positioning system (GPS) measurements of how Earth's surface moves in response to plate tectonic processes. In this study, we use results from a tectonic and earthquake cycle model based on GPS measurements to identify the locations and magnitudes of potential earthquakes on 16 of the world's largest faults. Along these faults, two tectonic plates are coupled, or stuck together, to varying degrees: on some portions, the two plates slide freely past each other, and in other regions, the two plates are stuck, so the nearby portions of the plates themselves undergo distortion, which can be tracked using GPS. Studies of recent earthquakes suggest that the region of the fault that was stuck together prior to the earthquake is where the slip took place. With this in mind, we use a model of global fault coupling to find regions where additional great earthquakes may occur. We suggest that nearly all of the world's subduction zones, as 
${ }_{47} \quad$ well as the fault beneath the Himalayas, could produce a magnitude 9 or greater earth$48 \quad$ quake. 


\section{Introduction}

Forecasting the occurrence of potential seismicity is a fundamental goal of earthquake science. In addition to providing an outlook on future earthquake activity, forecasts provide context for the interpretation of past seismicity, fault geometry, and presentday deformation rates. Geological and historical records provide estimates of earthquake activity including the sizes and recurrence intervals of large events. For example, since 1900, five magnitude $\geq 9.0$ and 94 magnitude $\geq 8.0$ earthquakes have occurred across the globe (USGS Earthquake Catalog Search, 2021).

At global scales, potential seismicity has been estimated in at least two modern ways. The first uses interseismic strain rates derived from geodetic velocities to produce estimated rates of potential shallow seismicity (Bird et al., 2010, 2015; Kreemer et al., 2014). A second approach has been to analyze models of three-dimensional fault morphology (Basili et al., 2008; Hayes et al., 2012, 2018; Plesch et al., 2007) to place constraints on the total fault area available for earthquakes to rupture across, and to assess the planarity of potential rupture surfaces to better understand the location of geometric barriers to great earthquake propagation (Plescia \& Hayes, 2020).

Block models can also be used to interpret interseismic geodetic data to provide constraints on fault slip rates and the spatial distribution of fault coupling (McCaffrey, 2002; Meade \& Loveless, 2009), and in turn, the spatial extent of interseismic coupling may identify potential earthquake ruptures (Loveless \& Meade, 2015). Here we make such identifications using results from a global block model (GBM) (Graham et al., 2018) that links GPS data to fault geometry models by estimating interseismic coupling across $7.5 \times$ $10^{6} \mathrm{~km}^{2}$ of dipping fault system comprising 15 subduction zones and the Himalayan Range Front. This approach augments previous GPS-based approaches with the addition of a physics-based model for interseismic fault system activity and supplements fault system morphology approaches with geodetically informed coupling distributions. At a conceptual level, it is essentially an extension of the seismic gap hypothesis (McCann et al., 1979), adding geodetically derived information about the degree of coupling on a particular gap. This approach also provides a means to complement the paleoseismic record by providing an observation-driven approach for constraining potential earthquake sizes even in regions where we do not have detailed or representative geological records (e.g., Hough, 2013). 
Geodetically constrained estimates of interseismic subduction zone coupling have been used to retroactively map the rupture areas of the $\mathrm{M}_{\mathrm{W}}=9.0-9.1$ Tohoku-oki, Japan (Hashimoto et al., 2009; Loveless \& Meade, 2010, 2011), $\mathrm{M}_{\mathrm{W}}=8.8$ Maule, Chile (Moreno et al., 2010), and $\mathrm{M}_{\mathrm{W}}=7.6$ Nicoya, Costa Rica (Protti et al., 2014) earthquakes. In these cases, regions of the subduction zone that ruptured coseismically were identified as partially to strongly coupled prior to the events. However, whether there is a critical coupling level that may serve as a barrier to rupture propagation is unclear. For the Tohoku-oki earthquake, a region of the Japan subduction zone bounded by an interseismic coupling threshold of 0.3 (where interseismic slip deficit was accumulating at 0.3 of the plate convergence rate) approximated the limits of the coseismic rupture (Loveless \& Meade, 2011). For the Maule and Nicoya earthquakes, coupling thresholds of 0.8 and 0.5 , respectively, may have effectively represented the spatial limits of the coseismic rupture (Moreno et al., 2010; Protti et al., 2014). The challenge of assessing any such correlation is exacerbated by disparities in inverse problem parameterization and regularization from study to study. For example, different choices in smoothing regularization and a priori distribution of aseismic slip may lead to distinct estimates of interseismic coupling and coseismic slip distributions even if the same data are used (Loveless \& Meade, 2011).

The interpretation of apparent interseismic coupling is not without ambiguity. The coupled regions estimated in the GBM are represented as spatially continuous, at least at length scales $>50 \mathrm{~km}$. This is not an assertion of physical continuity of partial coupling but rather an effective numerical parameterization that reflects the number and location of available geodetic observations and geometric representation of fault interfaces. Variations in coupling at much shorter length scales (e.g., Lay et al., 2012) may be below the level of current geodetic resolution given their depth and the attenuation of signals through the elastic crust, and/or alternative estimation methods may need to be developed to estimate such small variations. At the level of effective kinematic utility there are at least two perspectives that may guide the interpretation of inferred coupling regions. The first is that based on the idea that these contemporary estimates may be validated by their consistency with rupture areas of earthquakes from the historical or geologic records. In this sense, geodetically inferred coupling distributions are seen as possible representations of earthquakes that are characteristic in nature (Sieh, 1996). A second interpretation is that geodetically inferred coupling distributions represent a 
snapshot of time-varying fault coupling that may, or may not, be spatially consistent with rupture areas of past events. In this view, present-day behavior may be best connected to the rupture areas of future seismic events. While here we assume that contemporary coupling distributions are representative of average behavior over an earthquake cycle, estimates of short-term (sub-decadal) fluctuations in subduction zone coupling (e.g., Nishimura et al., 2004; Mavrommatis et al., 2014; Loveless et al., 2016) provide evidence that static coupling distributions may only be approximations. Finally, an intermediate concept may unify these interpretations, with contemporary coupling seen as reflecting long-term stability in fault rheology that governs the distribution of the largest earthquakes, with some superposition of shorter-term, shorter-wavelength variations in fault behavior that may influence the distribution of pending earthquakes.

\section{Geodetic constraints on potential earthquake sizes}

We develop potential earthquake scenarios from interseismic coupling distributions derived from a global block model (GBM) (Graham et al., 2018). While these inferences of coupling may differ from prior geodetically constrained coupling estimates, this single source provides consistency across subduction zones and considers intermediate and far-field elastic interactions. Further, the inferred plate motions and fault slip rates are all kinematically consistent with each other, eliminating another potential source of modelto-model discrepancies. Taken together, this uniform set of interseismic subduction zone coupling estimates forms the basis for calculating potential earthquake sizes across subduction zones globally.

The GBM approach used here follows the classical quasi-static block model formulation (McCaffrey, 2002; Meade \& Loveless, 2009; Murray \& Segall, 2001), which assumes that nominally interseismic GPS velocities arise from the combined contributions of plate (block) rotations and a first-order representation of earthquake cycle activity. That approximation posits that, during the nominally interseismic phase of the earthquake cycle, faults slip to a limited extent, allowing accumulation of slip deficit. In the GBM, consisting of 307 plates bounded by 446,870 km of fault length (Graham et al., 2018), we have assumed that most faults are fully coupled during the interseismic period, accumulating slip deficit at the relative block motion rate, and that 16 subduction zones may have spatially variable coupling. Each of these interfaces is represented as a mesh of triangular dislocation elements (TDEs), constructed using the open-source meshing pro- 
gram Gmsh (Geuzaine \& Remacle, 2009) with fault geometries expressed as depth contours derived from geophysical constraints. Nine of the subduction interface geometries incorporated into the GBM are based on the Slab1.0 model (Hayes et al., 2012) and the remaining seven are based on the following sources: Mexico/Central America-combination of (Radiguet et al., 2012) in Mexico and Slab1.0 in Central America; New Zealand (Wallace \& Beavan, 2010a); Japan/Nankai/Sagami (Loveless \& Meade, 2010) and references therein; Himalaya (Hubbard et al., 2016); and Caribbean (Symithe et al., 2015). For each TDE in the GBM, we estimate a slip deficit rate in the strike-parallel and dip-parallel directions, and we define coupling on each element as the slip deficit rate normalized by the relative block motion rate projected onto the element's geometry (Figure 1).

To determine potential rupture areas on each fault mesh, we find all TDEs with estimated coupling above a chosen threshold (e.g., $\geq 0.5$ coupling, where the estimated slip deficit rate is half of the relative plate motion rate). This yields a subset of mesh elements that may or may not be connected to one another. Selected subsets group into a relatively small number $(\leq 18)$ of clusters across each interface, which we interpret as defining rupture areas for potential earthquakes at that coupling level. Element clusters may be contiguous because of the physics underlying coupling patterns and/or as a result of the smoothing regularization used in estimating slip deficit rates.

Coupling cluster area, $A$, is related to potential earthquake moment magnitude, $\mathrm{M}_{\mathrm{W}}$, through an empirical scaling relationship previously developed for subduction zone earthquakes (Allen \& Hayes, 2017): $\log _{10} A=-3.63+0.96 \mathrm{M}_{\mathrm{W}}$. We chose this scaling law for consistency with related global earthquake hazard assessment though others may be viable as well (Murotani et al., 2013; Ye et al., 2016). Allen and Hayes (2017) also presented an alternative set of two linear area-magnitude relationships, with a higher slope applying to earthquakes of $\mathrm{M}_{\mathrm{W}} \leq 8.63$ and a lower slope for events of $\mathrm{M}_{\mathrm{W}}>8.63$, but we chose to use their uniform area-magnitude scaling to estimate the coupling-based earthquakes, as it yields earthquakes of peak $\mathrm{M}_{\mathrm{W}} \sim 10$, as opposed to $\mathrm{M}_{\mathrm{W}} \geq 12$ projected by the lower-slope variant.

In addition to estimating potential earthquake rupture areas, we also calculate recurrence intervals using slip deficit rates constrained from the GBM. To do so, we convert the potential earthquake moment magnitude to seismic moment, $\mathrm{M}_{0}$, using the relationship $\mathrm{M}_{0}=10^{\left(1.5 \mathrm{M}_{\mathrm{W}}-9.05\right)}$, where the seismic moment is expressed in $\mathrm{N} \cdot \mathrm{m}$ (Hanks 
\& Kanamori, 1979). As seismic moment is defined as $\mathrm{M}_{0}=\mu A s$ (Aki, 1972), where $\mu$ is shear modulus (taken here to be $30 \mathrm{GPa}$ ), $A$ is total rupture area, and $s$ is slip magnitude across the rupture area, we calculate the recurrence interval, $r$, of each potential earthquake as $r=\mathrm{M}_{0} / \mu A \dot{s}$, where $A \dot{s}$ is the sum of products of area and slip deficit rate across the triangular elements in the coupled cluster.

We apply these magnitude and recurrence interval calculations to each subduction zone interface to develop a suite of rupture scenarios (Figures 2; S1-S8) based on spatial patterns of coupling that span weak ( $\geq 0.1 ; 0$ coupling means free slip) to strong $(\geq 0.9$; coupling of 1 means slip deficit equal to relative plate motion). In general, weak coupling rupture scenarios feature large area, high magnitude potential earthquakes, which become smaller in area and magnitude, and in many cases are segmented into multiple events, at higher coupling thresholds (Figure 3). At the same time, projected recurrence intervals decrease with increasing coupling threshold, principally because higher coupling corresponds to faster slip deficit rates, which appear in the denominator of the recurrence interval calculation. As a result, even though the lowest coupling increments outline the largest potential earthquakes, rupture scenarios suggested by higher coupling thresholds may be considered more hazardous, because the proposed magnitudes are still large and recurrence intervals are shorter.

Throughout, we use the term "potential earthquakes" to refer to those that may rupture spatially contiguous regions inferred from the GBM constrained by geodetic observations of nominally interseismic surface motions. In reality, several of what we call potential earthquakes have already occurred, postdating the start date of constraining geodetic observations. These earthquakes include the 2005 Nias (Sumatra), 2007 Sumatra, 2010 Maule (Chile), 2011 Tohoku-oki (Japan), 2012 Nicoya (Costa Rica), 2014 Iquique (Chile), and 2015 Illapel (Chile) events. Though we combine discussion of recent events with future earthquake scenarios, their occurrence in many cases is consistent with our methodology in that the rupture areas coincide with regions of spatially contiguous coupling. 


\section{A survey of potential earthquakes scenarios by region}

\subsection{Aegean}

Geodetically constrained estimates of interseismic coupling along the Aegean plate boundary (Hellenic Trench) are few due to the sparsity of GPS (Cocard et al., 1999; McClusky et al., 2000; Reilinger et al., 2010), relatively low convergence rates $(\sim 30 \mathrm{~mm} / \mathrm{yr}$, which leads to a relatively low signal to noise ratio), and a focus on regional tectonics rather than earthquake cycle processes. Coupling estimates at the Aegean subduction zone have been inferred to be $\leq 0.2$ in the vicinity of Crete, which hosts a majority of the near-trench GPS stations in the region (Reilinger et al., 2010; Vernant et al., 2014). GBM coupling estimates (Figure 4; focused on the Hellenic trench splay fault) along the length of Crete and north towards the Peloponnese are similarly low $(\leq 0.3)$ covering a region consistent with a $\mathrm{M}_{\mathrm{W}}<7.2$ event. However, to the east of Crete and south of the Dodecanese, we infer an obliquely slipping area coupled at $\geq 0.8$ with a potential rupture area consistent with $\mathrm{M}_{\mathrm{W}}>8.0$ events recurring every $143-267$ years. Similarly, to the west of the Peloponnese we infer a region of intermediate coupling $(\leq 0.6)$ over a contiguous area consistent with $\mathrm{M}_{\mathrm{W}}>7.0$ events that recur every 110-319 years.

\subsection{Alaska and the Aleutians}

The greater Alaska subduction zone was home to the $1964 \mathrm{M}_{\mathrm{W}}=9.2$ earthquake that ruptured an area along the trench from $145^{\circ} \mathrm{W}-155^{\circ} \mathrm{W}$. Previous block models have been developed to assess the consistency of GPS velocities with prior constraints on spatially variable subduction zone coupling (Elliott \& Freymueller, 2020). These models are consistent with pervasive near-trench creep near $156^{\circ} \mathrm{W}$, increasing to fully coupled at $152^{\circ} \mathrm{W}$ before becoming highly heterogeneous near $146^{\circ}$, with the transition between strong and weak coupling approximately collocated with the boundary between the great 1964 earthquake and the $\mathrm{M}_{\mathrm{W}}=8.2$ earthquake in 1938. West of the 1938 earthquake and the creeping Shumagin gap, the Aleutian arc may have ruptured entirely in a series of earthquakes over a 70 -year long interval $(1946,1957,1965,1986,1996$, and 2003). The GBM indicates relatively high near-trench interseismic coupling for the Alaska subduction zone (Figure 5), extending from $146^{\circ} \mathrm{W}$ to $155^{\circ} \mathrm{W}$ for a coupling coefficient of 0.9 , similar to the rupture area of the 1964 earthquake, and expanding monotonically westward to $164^{\circ} \mathrm{W}$ for coupling coefficients down to 0.1 , which also encompasses the 1938 
earthquake region. Effectively coupled regions map into single $\mathrm{M}_{\mathrm{W}} \geq 9.0$ potential earthquakes for all coupling coefficients with a second $\mathrm{M}_{\mathrm{W}}=8.0$ earthquake centered at $164^{\circ} \mathrm{W}$ for the 0.2 coupling coefficient case. Estimated recurrence intervals for the $\mathrm{M}_{\mathrm{W}} \geq 9.0$ events decrease from 561 to 190 years with increasing coupling coefficients. Across the Aleutians Islands west of $165^{\circ} \mathrm{W}$, coupling is relatively poorly constrained due to sparse station coverage but near-trench coupling is present along its entire along-strike length at coupling coefficient $\leq 0.4$ (Figure 6), consistent with a contiguous sequence of coseismic ruptures (Freymueller et al., 2013). At higher thresholds, coupling is more spatially fragmented, consistent with multiple $7.7 \leq \mathrm{M}_{\mathrm{W}} \leq 8.9$ events, which may be interpreted as consistent with the alternating coupled and creeping patches identified by (Freymueller et al., 2013).

\subsection{Caribbean}

In the Caribbean, trench-normal subduction along the Lesser Antilles transitions to oblique convergence near Puerto Rico to strain partitioning between trench-normal convergence and plate boundary-parallel motion on the Septentrional and Enriquillo faults in Hispaniola. The GBM coupling estimates along the subduction zone are similar to those found by (Symithe et al., 2015) for both the Lesser Antilles portion of the arc and the northern portion of the margin adjacent to Puerto Rico and Hispaniola (Figure 7). However, we estimate higher coupling across the Lesser Antilles and an additional low coupling patch to the north of Puerto Rico. The coupling-based rupture areas along the Northern Hispaniola fault and the Puerto Rico Trench correlate well with historical events for both locations in 1946-1948, 1956, and 2003, and in 1787 and 1943, respectively (Manaker et al., 2008). Magnitudes ranging from 7.0-8.1 during the 1943-1953 earthquake sequence (Dolan et al., 1998) are consistent with GBM potential magnitude estimates. While the up-dip area of coupling offshore the Lesser Antilles is consistent with previous results, the trench is $\sim 200 \mathrm{~km}$ away from island arc GPS stations. Prior work to assess the resolving power of the local geodetic network suggested limits to the extent to which the depth of coupling could be determined (Symithe et al., 2015). GBM coupling estimates indicate that this region has the potential to produce magnitude $\mathrm{M}_{\mathrm{W}}=8.2-8.7$ earthquakes depending on the coupling fraction, similar to the $1843 \mathrm{M}=7.5-8.5$ Lesser Antilles earthquake (Bernard \& Lambert, 1988; ten Brink et al., 2011; Sykes et al., 1982; Feuillet et al., 2011; Hough, 2013). While the coupled region in the Lesser Antilles is sim- 
ilar to that in (Symithe et al., 2015), the GBM constrained recurrence interval is shorter due to the higher coupling fraction (2,000 vs. $\sim 200--650$ years $)$.

\subsection{Cascadia}

The Cascadia subduction has remained unruptured by events larger than magnitude 7.0 over the past $\sim 321$ years (Goldfinger et al., 2003). While representing only $5 \%$ of this time interval, GPS data from the last 20 years have been interpreted as consistent with prior interseismic coupling. Most GPS-based interseismic coupling estimates (Burgette et al., 2009; Delano et al., 2017; McCaffrey et al., 2000, 2007; Michel et al., 2019; Schmalzle et al., 2014; Wang et al., 2003; Yoshioka et al., 2005), with differing sets of assumptions about the potential for spatial overlap between strong coupling and locking, suggest $>50 \%$ interseismic coupling localized above $20-25 \mathrm{~km}$, with some suggestion of $\sim 10 \%$ at depths of 40-60 km depth (Yoshioka et al., 2005).

The Cascadia model inferred with the GBM (Figure 8) exhibits both near surface coupling, common to most GPS studies, and a coupling region that extends beneath the Olympic Peninsula at all coupling thresholds 0.1-0.9. At coupling values $\leq 0.4$ the coupling distribution also expands latitudinally at a depth $\sim 40 \mathrm{~km}$ to both the north and south of the Olympic Peninsula. While not extending south of $45^{\circ} \mathrm{N}$ in spatial extent, this deep coupled region is grossly consistent with the northern extent of previously inferred the banded coupling region (McCaffrey et al., 2000). The large contiguously coupled region near the trench maps to a $\mathrm{M}_{\mathrm{W}}=8.7-9.3$ earthquake with recurrence intervals of 239 to 899 years. At coupling coefficients of 0.7-0.9, a smaller coupled patch emerges at the southernmost up-dip part of the fault with an area consistent with $\mathrm{M}_{\mathrm{W}}=$ $7.8-7.9$ earthquakes occurring every $\sim 90$ years.

Previous estimates of interseismic coupling distributions have been used to guide coseismic rupture scenarios that simulate potential great earthquakes on the subduction interface (Frankel et al., 2018; Wirth et al., 2018). In these scenarios, purported slip is restricted to the shallowest portion of the subduction fault, with negligible rupture beneath $\sim 30 \mathrm{~km}$. This distribution of moment release is broadly consistent with GBM coupling estimates, with a notable exception beneath the Olympic Peninsula, where we infer coupling deeper than where the earthquake simulations place slip. 


\subsection{Himalaya}

Earthquake potential associated with the faults that underlie the Himalayan Range Front (HRF) has been of great interest because of high population density (Bilham et al., 2001) and enigmatic tectonics (England \& Bilham, 2015; C. Wobus et al., 2005). Geometrically there is a vast amount of fault area available to rupture in a large earthquake due to the extraordinarily shallow dips $\left(4^{\circ}\right)$ of the leading foreland faults (Avouac, 2003; Plescia \& Hayes, 2020) as well as the possible seismic activity on more steeply dipping faults located within the topographic front (C. W. Wobus et al., 2003; C. Wobus et al., 2005). Understanding the spatial extent of interseismic coupling here is particularly important because of the potential discrepancy between the historical record, which suggests $75 \%$ less moment release than would be anticipated over the past 200 years (Bilham et al., 2001), and the paleoseismic record, which has provided localized slip histories that have been interpreted with magnitude $9+$ seismic events rupturing into Nepal (Lave et al., 2005) and Bhutan (Le Roux-Mallouf et al., 2020).

The estimated HRF coupling distributions from the GBM are generally consistent with previous inferences or assumptions of HRF coupling: the shallowest 10-15 km of an approximated Main Frontal/Main Boundary thrust structure are coupled at 70-90\% along most of the Himalayan arc (Ader et al., 2012; Bettinelli et al., 2006; Li et al., 2020; Ponraj et al., 2011; Stevens \& Avouac, 2015; Yadav et al., 2019; Dal Zilio et al., 2020). The only significant along-strike decrease in estimated coupling occurs near $78^{\circ} \mathrm{E}$, near where Dal Zilio et al. (2020) estimated a relatively high probability of low coupling. This spatially continuous estimate of HRF coupling yields a potential earthquake of $\mathrm{M}_{\mathrm{W}}=$ 9.0-9.3 over coupling levels from 0.1-0.9 (Figure 9) with recurrence intervals ranging from 546-1088 years and the greatest decreases in down dip coupling occurring west of $79^{\circ} \mathrm{E}$ longitude.

\subsection{Japan}

The four subduction zones along Japan's Pacific coast — the Japan-Kuril Trench offshore Hokkaido and northern Honshu, the Sagami Trough beneath central Honshu, the Nankai Trough under southwest Honshu, Shikoku, and Kyushu, and the Ryukyu Trench spanning the sparse Ryukyu Islands from Kyushu to northern Taiwan - feature varying areas, subduction rates and angles of obliquity, and physical properties. The long 
historical record of earthquakes (e.g., Utsu, 2004) in Japan allows for a spatial comparison with estimated GBM coupling patterns.

Loveless and Meade (2015) summarized potential rupture areas based on regionspecific interseismic coupling estimates (Loveless \& Meade, 2010, 2011), finding general agreement between regions of the Japan Trench, Sagami Trough, and Nankai Trough subduction zones coupled at $\geq 0.8$ and historical to recent patterns of seismicity. One clear exception to this correspondence was the $2011 \mathrm{M}_{\mathrm{W}}=9.1$ Tohoku-oki earthquake, which ruptured an area more consistent with the subduction interface estimated to be pre-seismically coupled at $\geq 0.3$ of the convergence rate.

The estimated coupling on the Japanese subduction zones from the GBM is generally spatially smoother than in the local models (Loveless \& Meade, 2010, 2011), and so coupling concentrations and, in turn, projected rupture areas are less distinct. For coupling ratios of $0.1-0.5$, we estimate a single $\mathrm{M}_{\mathrm{W}} \geq 9.3$ earthquake that spans the entire length of the Japan Trench (Figure 10), with greatest width offshore central Honshu and Hokkaido and reduced depth extent along northern Honshu $\left(40^{\circ} \mathrm{N}\right)$. Recurrence intervals for this massive event are projected to be 257-399 years, substantially shorter than the $\sim 600$-year duration between the 2011 Tohoku-oki earthquake and previous great earthquakes on the section of the fault that it ruptured, which occurred in 1454 and 869 (Satake, 2015). At coupling ratios $\geq 0.6$, this single potential earthquake is split into multiple smaller yet still great earthquakes. For the regularization used in the GBM, the rupture scenario ( $\mathrm{a} \mathrm{M}_{\mathrm{W}}=8.8$ earthquake with recurrence interval of 141 years) corresponding to coupling $\geq 0.6$ is most similar to the along-strike extent of the 2011 Tohokuoki earthquake.

On the Nankai Trough subduction zone (Figure 11), we also find a single, very large earthquake $\left(M_{W} \geq 8.8\right)$ spanning nearly the entire length of the subduction zone for coupling ratios $<0.9$. Only at the highest coupling interval of $\geq 0.9$ do we estimate multiple events: one in the Tokai region, east of $135^{\circ} \mathrm{E}$, and one beneath western Shikoku and the Bungo Channel between Shikoku and Kyushu. The Nankai interface has been proposed to rupture in variable styles across three sections: the Nankai, Tonankai, and Tokai regions (e.g., Ando, 1975; Kodaira et al., 2006). The most recent events were a pair of great earthquakes in 1944 on the Nankai segment $\left(\mathrm{M}_{\mathrm{W}}=8.4\right)$ and in 1946 on the adjacent Tonankai segment $\left(\mathrm{M}_{\mathrm{W}}=8.1\right)$, and historical records suggest a $\sim 100-150$ year 
recurrence interval for prior great earthquakes along the trough (Ando, 1975), most comparable to the 89 and 151-year recurrence intervals for the two great earthquakes of the 0.9 coupling scenario.

On the Sagami Trough (Figure 12), all coupling increments feature a single cluster, corresponding to a projected earthquake of $7.7 \leq \mathrm{M}_{\mathrm{W}} \leq 8.2$, with corresponding recurrence intervals of 100-321 years. A recent study of Sagami Trough earthquake history (Ishibashi, 2020) suggests recurrence intervals of 140-270 years for events similar in magnitude to the most recent earthquake, the $1923 \mathrm{M}_{\mathrm{W}}=7.9$ Kanto earthquake.

\subsection{Kamchatka}

The Kamchatka Peninsula lies between the westernmost Aleutians and the northernmost Kuril Islands and was home to the $6^{\text {th }}$ largest recorded earthquake, the $\mathrm{M}_{\mathrm{W}}=$ 9.0 Severo-Kurilsk earthquake of 1952. Estimated GBM coupling distributions at all thresholds show coupling extending downdip from the trench (Figure 13). In general, the downdip and lateral extents of coupling expand monotonically with decreasing coupling coefficient as potential earthquake sizes grow from $\mathrm{M}_{\mathrm{W}}=8.5$ to $\mathrm{M}_{\mathrm{W}}=9.0$. Coupling is strongest off the southern part of the peninsula, similar to the estimation of Bürgmann et al. (2005), but lacks a localized downdip highly coupled region at $52^{\circ} \mathrm{N}$ (Bürgmann et al., 2005), though this may stem in part from our assumption that the slip deficit rate decreases to zero at the downdip extent of the modeled fault geometry. The 1952 earthquake ruptured the southern portion of the Kamchatka subduction interface, with other $\mathrm{M}_{\mathrm{W}}=$ 7.8 to $\mathrm{M}_{\mathrm{W}}=8.2$ earthquakes in the $19^{\text {th }}$ and $20^{\text {th }}$ centuries taking place across rupture areas smaller than imaged by our smooth coupling distribution. For the single rupture area, we estimate a recurrence interval of 67-222 years, with the high end being similar to the 215 years between the 1952 earthquake and the preceding event of a similar magnitude, which occurred in 1737 (Johnson \& Satake, 1999)

\subsection{Mexico and Central America}

The behavior of the subduction zone along the west coast of Mexico and Central America varies along-strike as the boundary transitions from Rivera-North America to Cocos-North America convergence in Mexico, to Cocos-Caribbean convergence from Guatemala to Costa Rica, and finally to Nazca-Caribbean convergence in Panama. The Rivera-North 
America plate boundary is defined by steeper subduction than the adjacent Cocos plate. The $1995 \mathrm{M}_{\mathrm{W}}=8.0$ Colima-Jalisco earthquake (Hutton et al., 2001) and earlier $\mathrm{M}_{\mathrm{W}}=$ 8.2 and $\mathrm{M}_{\mathrm{W}}=7.8$ events in 1932 (Singh et al., 1985) approximately correspond to a $\mathrm{M}_{\mathrm{W}}=7.4-7.9$ event inferred from the GBM at 40-80\% coupling with corresponding recurrence intervals of 53-118 years (Figure 14). Weaker coupling (0.1-0.3) spans the Rivera-Cocos boundary, but whether an earthquake rupture would propagate across the distinct plates remains to be seen. Strong coupling with along-strike variations characterizes the Cocos portion of the Mexico subduction zone with frequent (several per decade) $\mathrm{M}_{\mathrm{W}}=7$ earthquakes and many slow slip events (SSEs) (e.g., Correa-Mora et al., 2008; Radiguet et al., 2012; Graham et al., 2015; Rousset et al., 2017). Suárez et al. (1990) estimate the region is capable of producing $\mathrm{M}_{\mathrm{W}}=8$ events. GBM coupling ratios $\geq 0.4$ patches could combine to produce a $\mathrm{M}_{\mathrm{W}}=9$ event or $\mathrm{M}_{\mathrm{W}}=8$ events if fewer potential rupture areas are involved at any given time. The potential for a $\mathrm{M}_{\mathrm{W}}=9$ earthquake is contingent on lateral extent as well as rupturing the portion of the plate interface that accumulates and releases strain as slow slip. Estimated recurrence intervals for $\mathrm{M}_{\mathrm{W}} \geq 9.4$ range from 640-1005 years depending on extent and $\sim 100-200$ years for $\mathrm{M}_{\mathrm{W}}=$ 8-class earthquakes. Coupling patches of $\geq 0.7$ correspond with historical earthquakes observed since 1900 (figure 14).

Guatemala marks a transition from strong to weak coupling moving southeast along the coast to El Salvador (Ellis et al., 2015). $\mathrm{M}_{\mathrm{W}}=7-8$ events have ruptured most of this portion of the plate interface, potentially releasing $50 \%$ of plate motion, though seismic observations of these events are minimal (White et al., 2004). There were $\mathrm{M}_{\mathrm{W}}=$ 7 earthquakes off the coasts of Guatemala and El Salvador in 2012, the latter producing a tsunami indicative of shallow rupture (Borrero et al., 2014; Geirsson et al., 2015). Low coupling on the plate interface off the coast of El Salvador is correlated with lower historical seismicity since 1900 and strain partitioning on the crustal sliver fault that is near fully coupled (Correa-Mora et al., 2008). We estimate shallow coupling and rupture patches that correlate with historical seismicity at $40-60 \%$ coupling. At $\leq 30 \%$ coupling, again the possibility for linking rupture areas creates the potential for a $\mathrm{M}_{\mathrm{W}} \geq$ 9.4 event. Off the coast of Guatemala coupling thresholds 0.4 and 0.5 have the potential to produce a $\mathrm{M}_{\mathrm{W}}=8.4$ or 8.1 event with a recurrence interval of 152 or 93 years, respectively. 
To the southeast of El Salvador and towards Nicaragua, a region of zero coupling transitions to a strongly coupled segment in the source region of the $1992 \mathrm{M}_{\mathrm{W}}=7.7$ Nicaragua earthquake (e.g., Kanamori \& Kikuchi, 1993; Satake, 1994; Ihmlé, 1996). Strong coupling beneath the Nicoya Peninsula of Costa Rica is well documented (e.g., Feng et al., 2012; Kobayashi et al., 2014) and correlated with the eventual $\mathrm{M}_{\mathrm{W}}=7.6$ earthquake rupture in 2012 (e.g., Protti et al., 2014). Costa Rica is well known for slow slip events both up-dip and down-dip of the 2012 rupture area releasing $80-90 \%$ of the accumulated strain in these regions (Dixon et al., 2014). Coupling beneath the Osa and Burica peninsulas of Costa Rica and Panama is correlated with subduction of the Cocos Ridge and three $\mathrm{M}_{\mathrm{W}}>7$ earthquakes since 1900 (Kobayashi et al., 2014). The GBM potential ruptures correlate well with the observed seismicity at coupling fractions of 0.4-0.7. Such earthquakes could occur every $\sim 40-80$ years (figure 14). We also find the potential for a mid to high $\mathrm{M}_{\mathrm{W}}=8$ earthquake at coupling fractions of $0.1-0.3$ from southern Nicaragua through the Nicoya, Osa, and Burica peninsulas with a recurrence interval between 182 and 331 years. This is consistent with a calculation by (Carvajal-Soto et al., 2020) of the potential for $\mathrm{M}_{\mathrm{W}} \geq 8$ earthquakes in the region.

\subsection{New Zealand}

Along the Hikurangi subduction zone, the Pacific plate subducts obliquely beneath the North Island of New Zealand at rates of 20-60 mm/yr (Wallace et al., 2004). GBM estimates of interseismic coupling are generally consistent with those of Wallace, Barnes, et al. (2012) with deep and strong coupling in the south transitioning to shallower and weaker coupling in the north (Figure 15). The Hikurangi margin is known for its diverse SSEs, which indicate a range of strain release along the plate boundary. In the south, SSEs are deep (25-40 km depth), long-lasting ( $\sim 1$ year), and occur every $\sim 5$ years (Wallace \& Beavan, 2006, 2010b). Along the central and northern portion of the margin, SSEs occur at shallower depths $(<15 \mathrm{~km})$, are shorter in duration $(<1$ month), and are more frequent ( 1-2 year recurrence) (Wallace \& Beavan, 2010a; Wallace, Beavan, et al., 2012). More recently, an SSE has been documented beneath the northern portion of the South Island following the 2016 Kaikōura earthquake (Wallace et al., 2018). Comparisons of moment accumulation rate between SSEs with average interseismic moment accumulation show that SSEs are an important part of strain release in New Zealand (Wallace \& Beavan, 2010b). Based on paleoseismic observations, Wallace et al. (2014) suggest that 
slow slip regions in New Zealand can also rupture during large coseismic events. For example, a shallow SSE in 2014 occurred on the part of the fault that ruptured in a tsunamigenic earthquake in 1947 (Wallace et al., 2016). With a larger fault area available for cosesimic rupture there exists a higher potential for great earthquakes.

With a historical record of less than 170 years, the seismic potential of this margin is not well known. The largest recorded subduction earthquakes were two $\mathrm{M}_{\mathrm{W}}=$ 7 events in 1947 along the northern end of the Hikurangi margin (Webb \& Anderson, 1998; Doser \& Webb, 2003). However, geodetic and paleoseismic data suggest that earthquakes $\mathrm{M}_{\mathrm{W}} \geq 8$ are possible (Wallace et al., 2014; Clark et al., 2019) and the GBM estimates are consistent with this (Figure 15). At coupling intervals between 0.2 and 0.9 we estimate a $\mathrm{M}_{\mathrm{W}} \geq 8.5$ event with the rupture in the southern part of the margin and recurrence intervals that vary from 500-1,000 years. These results are consistent with geodetic estimates of rupture magnitude and recurrence by Wallace and Beavan (2010b). The $\mathrm{M}_{\mathrm{W}}=71947$ earthquakes in the northern part of the margin are consistent with a rupture area at the 0.2 coupling interval with an estimated recurrence interval of 265 years. Whole-margin rupture, capable of producing a $\mathrm{M}_{\mathrm{W}}=9$ event, is predicted at a coupling ratio of 0.1 with an estimated recurrence interval of $\sim 1350$ years (Figure 15). Using Holocene coseismic coastal deformation and tsunami deposits, Clark et al. (2019) found the strongest evidence for whole margin rupture occurred 870-815 years BP where the southern and central portions of the margin show significant vertical coastal deformation and tsunami runups $\sim 9 \mathrm{~m}$ in the north. Earthquakes that occurred 3930-3780 and 1355-1300 years BP may also have ruptured the whole margin but there is less compelling evidence than for the 870-815 years BP event (Clark et al., 2019). Wallace et al. (2014) also found widespread evidence for whole-margin coseismic rupture 7100 years $\mathrm{BP}$ and note that it likely also included rupture of upper plate faults. Based on observations of Holocene coseismic uplift at multiple sites, Wallace et al. (2014) estimated a recurrence interval of 1,000-1,500 years for great earthquakes along the Hikurangi subduction zone. Paleoseismic evidence is thus consistent with GBM modeling estimates of a whole-margin rupture and the potential for great $\mathrm{M}_{\mathrm{W}}=9$ earthquakes in New Zealand.

\subsection{South America}

Great earthquakes along the South American (Andean) subduction zone have been documented over the past several centuries on the basis of historical damage assessments 
(Beck et al., 1998; Comte \& Pardo, 1991; Kelleher, 1972) and contemporary geophysical observations, and the purported rupture areas of these events show correlation with regions we estimate to be partially to strongly coupled. Along the northern Andean subduction interface, beneath Ecuador and Colombia, there has been variable rupture behavior over the past 100 years. In 1906, a magnitude 8.6 earthquake struck, followed in the subsequent decades by smaller events (1942, magnitude 8.3 and 1958, magnitude 7.9) within the same rupture area (Kelleher, 1972). This spatial pattern mimics that of the estimated coupling (Figure 16), with the coupling threshold of $\geq 0.3$ spanning the 1906 rupture area and patches of coupling $\geq 0.6$ coinciding with the two smaller events at latitudes $\sim 2^{\circ} \mathrm{S}$ and $3^{\circ} \mathrm{N}$. Between about $4^{\circ} \mathrm{S}$ and $12^{\circ} \mathrm{S}$, there are no regions coupled $\geq 0.3$, which is consistent with a spatial gap in the historical record of large earthquakes from central Ecuador to central Peru. Both coupling and past earthquake activity resume around the latitude of the subduction of the Nazca Ridge, around $13^{\circ} \mathrm{S}$.

The subduction zone offshore southern Peru has broken in a series of historical earthquakes dating back to the 1500s (Comte \& Pardo, 1991). Major M $>8.5$ events spanning $\sim 16-18^{\circ}$ occurred in 1604,1784 , and 1868 , while multiple smaller $(\mathrm{M}>7.8)$ earthquakes jointly ruptured this stretch of subduction zone in the late $17^{\text {th }}$ to early $18^{\text {th }}$ centuries, together defining a roughly 100-year recurrence interval for this segment over at least the past 500 years (Comte \& Pardo, 1991). This segment is spatially consistent with the northwestern end of the massive region of 0.3-0.5 coupling but inconsistent with stronger coupling values (Figure 16). The most recent great earthquake here, the $2001 \mathrm{M}_{\mathrm{W}}=$ 8.4 Arequipa event, broke the northwestern $\sim 2 / 3^{\text {rds }}$ of the 1604-1784-1868 rupture area, similar to the 1687 earthquake.

The southern $1 / 3^{\text {rd }}$ of this rupture area, along with the extent of the subsequent 1877 earthquake that spanned the Chile-Peru border to the Mejillones Peninsula (19$\left.23^{\circ} \mathrm{S}\right)$ are consistent with a segmented region of strong $(\geq 0.8)$ interseismic coupling (Figure 17), which features alternating shallow and deep sub-clusters. Offshore northernmost Chile region, the last great earthquake was the $2014 \mathrm{M}_{\mathrm{W}}=8.1$ Pisagua event, which was substantially smaller than the penultimate 1877 earthquake, leaving extant seismic hazard in this region (Hayes et al., 2014; Loveless et al., 2016). The latitudinal termination of the southernmost segment of this $\geq 0.8$ coupling region is consistent with the southern extent of the $1995 \mathrm{M}_{\mathrm{W}}=8.0$ Antofagasta earthquake. Farther south, a distinct $\geq 0.8$ coupling patch from $26-28^{\circ} \mathrm{S}$ is consistent with a $\mathrm{M}_{\mathrm{W}} \sim 8.4$ earthquake, 
similar to the size of the 1922 earthquake in this region. The next patch of strong coupling to the south $\left(\mathrm{M}_{\mathrm{W}}=8.4,30-34^{\circ} \mathrm{S}\right)$, is spatially correlated with a sequence of earthquakes in the past 80 years: the $1943 \mathrm{M}_{\mathrm{W}}=8.3,1985 \mathrm{M}_{\mathrm{W}}=7.8$, and $2015 \mathrm{M}_{\mathrm{W}}=$ 8.3 Illapel earthquakes. The $\geq 0.8$ coupling patch from $35-45^{\circ} \mathrm{S}$ is segmented, with the northern portion featuring deeper coupling and consistent in along-strike extent with the $2010 \mathrm{M}_{\mathrm{W}}=8.8$ Maule earthquake; the $\geq 0.9$ coupling in this region more directly mimics the Maule event. The southern stretch of this zone of strong coupling spans the rupture area of the great $1960 \mathrm{M}_{\mathrm{W}}=9.5$ Valdivia earthquake but is smaller in estimated magnitude, with the distinct $\geq 0.9$ coupling region corresponding to a $\mathrm{M}_{\mathrm{W}}=8.7$ event (with recurrence of 132 years), owing in part to the shallow restriction of estimated coupling.

In general, the great earthquake history of the Central to Southern Andean margin since the late $19^{\text {th }}$ century is consistent with the areas of strong $(\geq 0.8)$ coupling estimated by the GBM. Some of the larger patches of strong coupling show a technically contiguous but segmented geometry, and some of the sub-clusters are more consistent with historical rupture lengths. In general, the roughly century-long recurrence interval of great $\left(\mathrm{M}_{\mathrm{W}} \geq 8.0\right)$ earthquakes (Kelleher, 1972) is consistent with the repeat times estimated in the GBM, which span about 60 years for a $\mathrm{M}_{\mathrm{W}}=8.0$ event to 200 years for a $\mathrm{M}_{\mathrm{W}}=9.0$ earthquake. In the Northern Andean subduction zone, variable rupture behavior of smaller asperties rupturing individually, preceded by a contiguous rupture of those same asperities, could be considered consistent with the regions of estimated strong $(\geq 0.8)$ and moderate $(\geq 0.3)$ coupling, respectively.

\subsection{Sumatra}

The GBM represents subduction of the Indo-Australian Plate beneath Indonesia with a single fault interface spanning Sumatra to New Guinea (Figure S9). At the eastern extent of this model fault, estimated slip deficit rates exceed long-term convergence rates, which we interpret as a model artifact owing to low station density on the overlying islands and complexity of the local plate boundary zone. Because of this, and because the historical to paleoseismic earthquake record is better constrained on the SumatraAndaman (western) section of this subduction zone (Philibosian \& Meltzner, 2020), we focus on this region in our comparison of spatial patterns of coupling and earthquakes (Figure 18). 
Across coupling ratios $0.1-0.7$, GBM coupling estimates suggest a single, $\mathrm{M}_{\mathrm{W}}>$ 9.5 potential rupture area on the northern extent of the subduction zone from about $9^{\circ} \mathrm{N}-$ $6^{\circ} \mathrm{S}$, with recurrence intervals of $475-737$ years (Figure 18). At higher coupling ratios $(\geq 0.8)$, this rupture area is segmented into two, with a boundary around the location of the Batu Islands and Siburat $\left(\sim 1-2^{\circ} \mathrm{S}\right)$. This local minimum in coupling is consistent with what Philibosian and Meltzner (2020) deem a persistent barrier to earthquake rupture, suggested by a paucity of estimated historical rupture lengths that have crossed this region. The northern cluster in these rupture scenarios spans what Philibosian and Meltzner (2020) call the Andaman-Aceh and Nias segments of the subduction zone, although the former extends farther north than the modeled fault surface. The potential earthquake along this has a magnitude of $M W \geq 9.1$ (larger than the $2005 \mathrm{M}_{\mathrm{W}}=$ 8.6 Nias earthquake but smaller than the $2004 \mathrm{M}_{\mathrm{W}}=9.4$ Sumatra-Andaman earthquake) and a recurrence interval of 283-324 years. The southern cluster of the high-coupling scenarios is similar in extent to the Mentawai segment of Philibosian and Meltzner (2020), though we suggest a single large $\left(\mathrm{M}_{\mathrm{W}}=8.9-9.1\right)$ earthquake in this region, as opposed to the complicated rupture history documented in the geologic record. Past earthquakes with varying along-strike extent seem to combine to rupture the entire segment every 100-200 years (Philibosian \& Meltzner, 2020), broadly consistent with proposed recurrence intervals of 187-234 years for the single event across this cluster. Overall, the high coupling $(\geq 0.8)$ rupture scenarios are most consistent with the past earthquake record, but the paleoseismic documentation of smaller magnitude earthquakes indicates that the true rupture history is more complicated than may be resolvable given the current geodetic data distribution.

South and east of the island of Sumatra, GBM coupling estimates indicate generally low coupling, with a single $\mathrm{M}_{\mathrm{W}} \geq 9.0$ potential earthquake source that coincides roughly with the length of Java at coupling ratios $\leq 0.2$ (Figure S9). At coupling ratios of $\geq 0.3$, this area becomes segmented, with $\geq 4$ potential rupture areas of $7.5 \leq$ $\mathrm{M}_{\mathrm{W}} \leq 8.5$. No portion of this stretch of the subduction zone that has a coupling ratio $\geq 0.6$, and only two isolated patches where coupling is estimated to exceed 0.5 , each corresponding to a $\mathrm{M}_{\mathrm{W}} \sim 7.5$ earthquake. The eastern of these sources, located along the trench offshore the boundary between eastern Java and Bali, is spatially coincident with the $1994 \mathrm{M}_{\mathrm{W}}=7.6$ Java tsunami earthquake, estimated to occur at a shallow depth along the interface (Abercrombie et al., 2001). 


\section{Discussion}

\subsection{Summary of rupture patterns}

Using the geodetically constrained GBM estimates of spatially variable slip deficit distributions and coupling on global subduction zones, we have proposed potential rupture areas of recent to pending earthquakes. The putative rupture areas are based on increments of coupling, and the number, magnitude, and recurrence intervals of these earthquakes show some complication in their relationship to the coupling increments. In general, as the coupling increment increases, the fractional area of the fault exceeding that increment decreases, and therefore the moment magnitude of the corresponding proposed earthquake decreases. For regions featuring a single, contiguous cluster across most to all coupling increments (Alaska (Figure 5), Himalayas (Figure 9), Sagami (Figure 12), Kamchatka (Figure 13)), as the coupling fraction increases, the projected earthquake decreases monotonically in magnitude and recurrence interval.

However, in other regions that show greater variation in the spatial pattern of coupling, the relationship between earthquakes and coupling increment is less straightforward. In some cases, a single cluster at a low coupling increment becomes multiple smaller clusters at a higher increment, each of which corresponds to a lower magnitude earthquake. At progressively higher coupling increments, elements fall below the threshold and therefore are not considered part of a potential rupture area. For example, at the lowest coupling threshold, the Hikurangi subduction zone (Figure 15a), we find a single $\mathrm{M}_{\mathrm{W}}=9.0$ rupture area. At a coupling fraction of 0.2 , the shallow region north of $40^{\circ} \mathrm{S}$ is fragmented into two distinct patches corresponding to $\mathrm{M}_{\mathrm{W}}=6.5$ and $\mathrm{M}_{\mathrm{W}}=$ 7.7 events. These elements fall below the next coupling increment (0.3), but the deep part of the interface around $40^{\circ} \mathrm{S}$ becomes disconnected from the more strongly coupled patch south of $40^{\circ} \mathrm{S}$, and so two rupture areas are suggested: a deep $\mathrm{M}_{\mathrm{W}}=7.6$ and the larger $\mathrm{M}_{\mathrm{W}}=8.7$ that is a feature of all coupling increments along this subduction zone.

Globally, we find a peak number (12) of $\mathrm{M}_{\mathrm{W}} \geq 9.0$ earthquakes at a coupling fraction of $\geq 0.1$ (Figure 3), reflecting the large surface area of subduction zones that are at least weakly coupled. The peak number (41) of $\mathrm{M}_{\mathrm{W}} \geq 6.5$ earthquakes corresponds to the coupling fraction of $\geq 0.6$ scenarios, with progressively fewer potential earthquakes at higher coupling values. That the greatest number of earthquakes occurs at this moderate coupling threshold is consistent with very large potential ruptures defined by low 
coupling being fragmented into multiple clusters with increased coupling. The fact that more $\mathrm{M}_{\mathrm{W}} \geq 9.0$ events are consistent with the $\geq 0.7$ and $\geq 0.8$ coupling scenarios ( 5 and 6 , respectively) than the $\geq 0.6$ scenario (4) arises from the fragmentation of truly massive potential rupture areas $\left(\mathrm{M}_{\mathrm{W}} \geq 9.7\right)$ in Sumatra and South America into multiple $\mathrm{M}_{\mathrm{W}} \geq 9.0$ patches. Coupling fractions of $\geq 0.5$ and $\geq 0.8$ are consistent with the same number $(6)$ of $\mathrm{M}_{\mathrm{W}} \geq 9.0$ but differ in the total number of earthquakes (33 and 38 , respectively). This suggests that some contiguous rupture areas in the $\geq 0.5$ scenario are fragmented into smaller, lower magnitude clusters in the $\geq 0.8$ scenario, but the total number of $\mathrm{M}_{\mathrm{W}} \geq 9.0$ regions remains constant.

On all subduction zones considered in the global model, we force the downdip extent of the model geometry to have zero slip deficit, and therefore zero coupling, but we do not impose this constraint at the updip extent. In many subduction zones, the shallow portion of the plate interface nearest the trench is far from land-based geodetic monuments, and therefore the ability of these data to resolve slip processes on the shallow interface is limited (e.g., Loveless \& Meade, 2011). However, some seafloor geodetic observations suggest that coupling extends to near the trench (Gagnon et al., 2005; Yokota et al., 2015). Additionally, simple mechanical models suggest that the shallowest portion of a fault may be effectively forcibly coupled, at least partially, due to stresses imposed by strong coupling downdip (Almeida et al., 2018). We find in the GBM results that all subduction zones feature coupling to the trench along at least part of their length, but there is substantial variation in the strength of shallow coupling. For example, the entire length of the Japan Trench subduction zone is coupled $\leq 0.5$ along the updip edge, but only the Kuril segment (north of $\sim 42^{\circ} \mathrm{N}$ ) and isolated patches offshore Honshu are more strongly coupled $(\geq 0.8)$. Some plate boundaries feature substantial lengths that are not coupled at any depth, including the northern Ryukyu, central Caribbean (Figure 7), and central Peru (Figure 16) subduction zones. At all subduction zones, the largest potential earthquake we estimate includes elements along the updip edge of the modeled fault; the largest potential rupture area that we estimate anywhere that is disconnected from the updip edge is a $\mathrm{M}_{\mathrm{W}}=8.6$ offshore central Chile $\left(\sim 32^{\circ} \mathrm{S}\right)$, corresponding to a coupling increment of 0.7 (Figure $17 \mathrm{~g}$ ).

With the exception of the Aegean, Caribbean, and Sagami Trough regions, all subduction zones in the GBM accumulate slip deficit in a way that may be interpreted as consistent with a $\mathrm{M}_{\mathrm{W}} \geq 9.0$ earthquake for areas of coupling fraction $\geq 0.1$. However, 
it is worth noting that slip deficit rates in the Caribbean and Aegean are still consistent with very large, $\mathrm{M}_{\mathrm{W}} \geq 8.5$ earthquakes. Using a coupling fraction of $\geq 0.3$, we add the Hikurangi and Kamchatka subduction zones to the list of those inconsistent with a $\mathrm{M}_{\mathrm{W}} \geq 9.0$ earthquake. Examining strongly coupled regions ( $\geq 0.8$ ), we estimate slip deficit patterns only on the Alaska, Himalaya, South America (Chile), and Sumatra subduction zones that are consistent with a $\mathrm{M}_{\mathrm{W}} \geq 9.0$ event. At this same coupling increment, the Aegean, Aleutians, Cascadia, Caribbean, Japan, Nankai, Kamchatka, and Hikurangi have clusters capable of rupturing in $\mathrm{M}_{\mathrm{W}} \geq 8.0$ events, while the Mexico/Central America and Sagami Trough subduction zones feature clusters of coupled elements corresponding to at most a $\mathrm{M}_{\mathrm{W}}=7.8$ earthquake.

\subsection{Relationship with prior global earthquake forecasts}

The potential earthquake scenarios developed here may be considered in the context of prior global earthquake models. Estimated global seismicity rates constrained by past seismicity and contemporary strain rates (Bird et al., 2015) are not directly comparable to the GBM scenarios described here. Based on the observation that large instrumentally measured subduction zone earthquakes appear to occur along relatively flat sections of subduction zone interfaces (Bletery et al., 2016), a global slab geometry model (Hayes et al., 2018) has been used to develop geometrically constrained estimates of maximum sized earthquakes (Plescia \& Hayes, 2020). The central idea here is to search for areas of subduction zones with curvature variations comparable to those regions that have hosted historical earthquakes and then map these areas to potential earthquake sizes using empirical scaling relationships. The curvature-based approach is distinct from the GBM estimates here in that it does not rely on the kinematics of present-day deformation nor a representation of earthquake cycle physics. Further, the curvature-based model includes an accounting of many possible larger but not great earthquakes that could occur within a great earthquake rupture zone. Nonetheless, a cursory comparison shows similarity between the curvature-based and GBM estimates of maximum potential earthquake size (Table 1). The most notable difference is on the Caribbean subduction zone where the curvature-based estimate yields a maximum predicted rupture size of $\mathrm{M}_{\mathrm{W}}=$ 9.3 whereas the GBM estimate is a much lower $\mathrm{M}_{\mathrm{W}}=8.7$. The reason for this is that the GBM estimates of coupling show a gap in coupling near the northern Antilles, which effectively segments the north-south and east-west trending parts of the subduction zone 
interface. In other words, this geometrically smooth subduction zone has a kinematic gap in coupling where the plate interface appears to be actively creeping. However, low station density in this area may affect the coupling estimates in this region. In contrast, the GBM maximum potential estimate is higher than the curvature-based for the Central America subduction zone due to the fact that kinematic coupling estimates are spatially contiguous even across regions of geometric complexity. As was pointed out by Plescia and Hayes (2020), uncertainties in the mapping of surface area to magnitude limit accurate assessments of the largest potential magnitudes.

\subsection{Temporal complexity in interseimic slip processes}

In estimating potential earthquake magnitudes, this study assumes that all of the accumulated strain is released seismically. However, diverse observations across many subduction zones show that some accumulated strain is released by aseismic processes (e.g., slow slip and postseismic afterslip). For example, in the Guerrero seismic gap along the Mexico subduction zone, slow slip events (SSEs) are thought to release $75-100 \%$ of the accumulated strain (e.g., Radiguet et al., 2012; Graham et al., 2015). With a small remaining slip deficit, large earthquakes will have much longer recurrence intervals compared to other regions along strike. It is possible that in some places, if all of the accumulated strain is released by SSEs, no large earthquake will occur. Some studies of postseismic afterslip (e.g., Graham et al., 2014; Shrivastava et al., 2016; Jiang et al., 2018) and slow slip (e.g., Wallace et al., 2014) suggest that these aseismic processes can also occur in regions that exhibit stick-slip behavior. The key question is: In these regions of conditional stability, how much strain has accumulated at the time a large earthquake initiates? Over several seismic cycles, the answer may be too little strain and the region becomes a barrier to slip propagation. But in a subsequent seismic cycle for a large earthquake, the aseismic slip region may be at the end of its own strain release cycle. In this case, conditionally stable fault patches could rupture with the large earthquake and create a great earthquake.

It is also important to consider that we present only a static snapshot of potential earthquakes. However, several studies show temporal changes in subduction zone coupling (e.g., Nishimura et al., 2004; Mavrommatis et al., 2014; Loveless et al., 2016), which would lead to potentially different rupture scenarios. We present rupture scenarios assuming that the entire region at or above a certain coupling ratio (0.1 to 0.9$)$ were to 
rupture in a single event. The GPS velocities used to constrain the GBM are interpreted as a quasi-static measure of an underlying quantity (surface motion) that may vary throughout the decadal scale observation epoch. Specifically, the GPS velocities were derived by estimating a linear trend for each position time series, often isolating a time period over which the linear fit is an adequate representation of motion. However, there are estimates of time-dependent changes (e.g., Bedford et al., 2020) and persistent decadalscale unsteady motion in Japan (Heki \& Mitsui, 2013; Mavrommatis et al., 2014; Nishimura et al., 2004). These facts challenge attempts to argue that GPS observations from today may be considered secular with the exception of short term co- and post-seismic excursions. Further, implicit in elastic block models is the assumption that the GPS velocities can be interpreted exclusively in terms of plate motions and a first-order approximation of earthquake cycle processes that is invariant in time. The use of this approach means that any surface deformation associated with time-variable earthquake cycle deformation may be mapped to an artificial interseismic coupling distribution.

\subsection{GBM earthquake scenarios in the context of rupture dynamics}

Within the context of the kimematic earthquake cycle in the GBM we consider how coupling distributions may be compared with large seismic events generated by dynamic rupture simulations, which focus on more accurate representations of earthquake physics at smaller spatial scales. An argument for the spatial correlation between coseismic rupture and regions pre-seismically coupled as weakly as 30\% (Loveless \& Meade, 2011) can be derived from a consideration of the dynamic overshoot mechanism devised following the 2011 Japan earthquake (Kozdon \& Dunham, 2013). This work showed how inertial effects and frictional sliding laws can allow a rupture to propagate into weakly coupled regions. For the case of the Japan earthquake, this concept was used to explain how the Tohoku-oki earthquake might have ruptured the shallowest part of the Japan subduction zone to cause the high-magnitude near-surface slip that contributed to the generation of the earthquake-induced tsunami. While this mechanism can explain the up-dip propagation of slip in regions of little pre-earthquake coupling, the actual extent of preearthquake coupling in this region is unclear due to the low resolving power of on-shore geodetic observations (Loveless \& Meade, 2011). In fact, at one location along the Nazca subduction zone where trench-proximal interseismic seafloor geodetic observations do exist, strong interseismic near-surface has been coupling inferred (Gagnon et al., 2005). Thus, 
while our knowledge of pre-earthquake coupling along the shallowest part of subduction zones is poor, the consideration of this possible mismatch between regions of strong preseismic coupling and regions of coseismic rupture has prompted the development of concepts that may be more broadly applicable to how earthquakes propagate across regions of the lower interseismic coupling and potentially link together regions of greater interseismic coupling.

The question of how frequently and consistently ruptures might propagate across regions of low coupling is, unfortunately, quite complex. A subduction zone earthquake cycle simulation that included two large regions of velocity weakening material laterally separated by a narrower region of velocity strengthening material revealed expected patterns of strong coupling and weak coupling in the velocity strengthening and velocity weakening regions, respectively (Kaneko et al., 2010). However, over multiple seismic cycles, coseismic ruptures sometimes stayed localized on a single velocity weakening patch and sometimes were able to propagate across the intervening velocity strengthening patch. This diversity of behaviors and the dependence on past earthquake histories observed for the case of a planar fault with simple variations in material properties highlights the challenge of developing generalized heuristics for evaluating whether or not a particular low coupling region might fail in a proximal earthquake. Over the past century, global great earthquakes have shown variation in their spatial correspondence with the modern coupling distribution, including the aforementioned occurrence of the Tohoku-oki earthquake in a region coupled $\geq 0.3$, the Maule earthquake in $a \geq 0.8$ coupling region, and time-variable behavior offshore Colombia where a $\mathrm{M}_{\mathrm{W}}=8.9$ event occurred in a region coupled $<0.4$, but just a few decades later, a pair of $\mathrm{M}_{\mathrm{W}}=8.3$ and $\mathrm{M}_{\mathrm{W}}=7.8$ earthquakes happened in roughly the same area, with their own rupture areas more consistent with higher $(\geq 0.6)$ coupling thresholds. It is for this reason that we have limited our analysis to the case of calculating potential earthquake sizes associated with the geometric limits defined at a particular coupling interval rather than speculating about the possibility that composite ruptures emerge from the dynamic connections between strongly coupled patches.

\subsection{Strike-slip coupling}

A fundamental assumption in the GBM coupling estimates is that subduction zones may accommodate both dip- and strike-slip motion. Formally, we estimate slip deficit 
rates on subduction interfaces in directions parallel to both the strike and dip of the triangular dislocation elements used to represent the faults. As the intensity of coupling varies in space, so too must the rake of slip deficit. Differential plate motions at major plate boundaries suggest that $\sim 40 \%$ of plate motion may be oblique to the strike of the plate boundary (Sella et al., 2002; McCaffrey, 1996). Subduction zone coupling distributions in the GBM indicate strike-slip interseismic coupling with rates ranging up to $40+\mathrm{mm} / \mathrm{yr}$ on the Nazca subduction zone off the coast of Peru. These estimates are broadly consistent with the observation that differential plate motions at subduction zones are not perfectly convergent (e.g., DeMets et al., 1990; Sella et al., 2002). This prompts a revisiting of the kinematic question of how this oblique motion may be accommodated in the context of limited evidence for strike-slip components of subduction zone earthquakes (McCaffrey, 1992).

One hypothesis is that a significant fraction of the oblique plate motion may be accommodated by structures near but not on the subduction zone. Two kinematic mechanisms for this are strike slip faults in the hanging wall (e.g., Fitch, 1972; Beck Jr, 1983) and the occurrence of strike-slip dominated earthquakes within the oceanic plate seaward of the subduction trench (Ishii et al., 2013). The strike-slip dominated Sumatra fault in the hanging wall of the greater Indonesian subduction zone has been argued to accommodate most of the oblique plate motion (e.g., Fitch, 1972). In southeast Asia the Sumatra fault accommodates strike slip at 8-15 mm/yr (Bradley et al., 2017; Natawidjaja et al., 2017) and there is $\sim 10 \mathrm{~mm} / \mathrm{yr}$ of strike-parallel slip deficit at the subduction zone. However, it is not the case that these forearc slivers generally slip fast enough to accommodate all of the oblique plate motion. For example, in southern Japan the Median Tectonic Line is oriented parallel to the Nankai trench accommodates on $\sim 7 \mathrm{~mm} / \mathrm{yr}$ of the compared with $\sim 30 \mathrm{~mm} / \mathrm{yr}$ on the underlying subduction zone (Loveless \& Meade, 2010).

\section{Conclusions}

The future of large seismic events is uncertain and difficult to estimate from past seismicity due to the infrequency of events and the relative short duration of the historical record. In place of a statistical model for large earthquake occurrence, we developed a suite of subduction zone rupture scenarios based on a kinematic block model constrained by contemporary geodetic measurements. This class of model integrates the effects of 
both plate motions and an idealized representation of physics-informed kinematics of interseismic earthquake cycle processes. Centrally, developing potential rupture models that include decadal-scale slip deficit rates allows us to estimate earthquake recurrence intervals in addition to locations and magnitudes. While some of the potential earthquake locations and magnitudes may be compared with recent large earthquakes (Tohoku-oki, Maule), a more general challenge associated with all models of future great seismicity, including the global block model used here, is the direct testing against future earthquake activity, fundamentally because of the $100+$ year long inter-event time of associated large earthquakes in any given location. Given the challenge of short-term assessment of large earthquake forecasts, we suggest model validation and development may expand towards block models models that can explain the diversity of time-dependent coupling across the entire earthquake cycle.

\section{Acknowledgments}

This was work was, in part, supported by Harvard University. All input files for the global block model, including the block geometry, subduction zone meshes, and constraining geodetic data, are available at: https://github.com/brendanjmeade/reference_gbm. The block modeling software is available at: https://github.com/jploveless/Blocks. Most figures were produced using the Generic Mapping Tools, version 5 (Wessel et al., 2013). 


\begin{tabular}{|c|c|c|}
\hline Subduction zone & (Plescia \& Hayes, 2020) $M_{\text {flat }}$ & GBM $M_{\mathrm{W}_{\max }}$ \\
\hline Kamchatka & $9.5+$ & 9.0 \\
Sumatra & $9.5+$ & 9.7 \\
Central America & 9.3 & 9.6 \\
Alaska + Aleutians & $9.5+$ & 9.3 \\
South America & $9.5+$ & 10.0 \\
Cascadia & 9.2 & 9.3 \\
Caribbean & 9.3 & 8.7 \\
\hline
\end{tabular}

Table 1. A comparison of the maximum earthquake sizes inferred from contiguous potential rupture areas from PH2020 and the global block model. Only regions common to both studies are represented. The maximum (Plescia \& Hayes, 2020) magnitude was reported as 9.5+ and referred to as $M_{\text {flat }}$. The maximum size potential earthquake estimates from both the curvature analysis model and the kinematic coupling models are similar for most subduction zones with the exception of the Caribbean and Central America.

References cited only in Supplementary Information: Bevis et al. (1995); Ando et al. (2009)

\section{References}

Abercrombie, R. E., Antolik, M., Felzer, K., \& Ekström, G. (2001). The 1994 Java tsunami earthquake: Slip over a subducting seamount. Journal of Geophysical Research, 106, 6595-6608.

Ader, T., Avouac, J.-P., Liu-Zeng, J., Lyon-Caen, H., Bollinger, L., Galetzka, J., ... Flouzat, M. (2012). Convergence rate across the Nepal Himalaya and interseismic coupling on the Main Himalayan Thrust: Implications for seismic hazard. Journal of Geophysical Research: Solid Earth, 117(B4). doi: 10.1029/2011JB009071

Aki, K. (1972). Earthquake mechanism. Tectonophysics, 13(1-4), 423-446. doi: 10 $.1016 / 0040-1951(72) 90032-7$

Allen, T. I., \& Hayes, G. P. (2017). Alternative rupture-scaling relationships for subduction interface and other offshore environments. Bulletin of the Seismological 
Society of America, 107(3), 1240-1253.

Almeida, R., Lindsey, E. O., Bradley, K., Hubbard, J., Mallick, R., \& Hill, E. M. (2018). Can the Updip Limit of Frictional Locking on Megathrusts Be Detected Geodetically? Quantifying the Effect of Stress Shadows on NearTrench Coupling. $\quad$ Geophysical Research Letters, 45(10), 4754-4763. doi: 10.1029/2018GL077785

Ando, M. (1975). Source mechanisms and tectonic significance of historical earthquakes along the Nankai Trough, Japan. Tectonophysics, 27(2), 119-140. doi: 10.1016/0040-1951(75)90102-X

Ando, M., Nakamura, M., Matsumoto, T., Furukawa, M., Tadokoro, K., \& Furumoto, M. (2009). Is the Ryukyu subduction zone in Japan coupled or decoupled? - the necessity of seafloor crustal deformation observation. Earth, Planets and Space, 61(9), 1031-1039. doi: 10.1186/BF03352954

Avouac, J. P. (2003). Mountain building, erosion, and the seismic cycle in the Nepal Himalaya. In Advances in Geophysics, Vol 46 (Vol. 46, pp. 1-80). San Diego: Academic Press Inc.

Basili, R., Valensise, G., Vannoli, P., Burrato, P., Fracassi, U., Mariano, S., .. . Boschi, E. (2008). The Database of Individual Seismogenic Sources (DISS), version 3: Summarizing 20 years of research on Italy's earthquake geology. Tectonophysics, 453(1-4), 20-43. doi: 10.1016/j.tecto.2007.04.014

Beck, S., Barrientos, S., Kausel, E., \& Reyes, M. (1998). Source characteristics of historic earthquakes along the central Chile subduction zone. Journal of South American Earth Sciences, 11(2), 115-129.

Beck Jr, M. E. (1983). On the mechanism of tectonic transport in zones of oblique subduction. Tectonophysics, 93(1-2), 1-11.

Bedford, J. R., Moreno, M., Deng, Z., Oncken, O., Schurr, B., John, T., ... Bevis, M. (2020). Months-long thousand-kilometre-scale wobbling before great subduction earthquakes. Nature, 580(7805), 628-635. doi: $10.1038 / \mathrm{s} 41586-020-2212-1$

Bernard, P., \& Lambert, J. (1988). Subduction and seismic hazard in the northern Lesser Antilles: Revision of the historical seismicity. Bulletin of the Seismological Society of America, 78(6), 1965-1983.

Bettinelli, P., Avouac, J.-P., Flouzat, M., Jouanne, F., Bollinger, L., Willis, P., \& 
Chitrakar, G. R. (2006). Plate motion of India and interseismic strain in the Nepal Himalaya from GPS and DORIS measurements. Journal of Geodesy, 80, 567-589. doi: 10.1007/s00190-006-0030-3

Bevis, M., Taylor, F. W., Schutz, B. E., Recy, J., Isacks, B. L., Helu, S., .. Calmantli, S. (1995). Geodetic observations of very rapid convergence and back-arc extension at the Tonga arc. Nature, 374(6519), 249-251. doi: $10.1038 / 374249 \mathrm{a} 0$

Bilham, R., Gaur, V. K., \& Molnar, P. (2001). Himalayan Seismic Hazard. Science, 293(5534), 1442-1444.

Bird, P., Jackson, D. D., Kagan, Y. Y., Kreemer, C., \& Stein, R. S. (2015). GEAR1: A Global Earthquake Activity Rate Model Constructed from Geodetic Strain Rates and Smoothed Seismicity. Bulletin of the Seismological Society of America, 105(5), 2538-2554. doi: 10.1785/0120150058

Bird, P., Kreemer, C., \& Holt, W. E. (2010). A Long-term Forecast of Shallow Seismicity Based on the Global Strain Rate Map. Seismological Research Letters, 81 (2), 184-194. doi: 10.1785/gssrl.81.2.184

Bletery, Q., Thomas, A. M., Rempel, A. W., Karlstrom, L., Sladen, A., \& De Barros, L. (2016). Mega-earthquakes rupture flat megathrusts. Science, $354(6315), 1027-1031$.

Borrero, J. C., Kalligeris, N., Lynett, P. J., Fritz, H. M., Newman, A. V., \& Convers, J. A. (2014). Observations and modeling of the August 27, 2012 earthquake and tsunami affecting El Salvador and Nicaragua. Pure and Applied Geophysics, 171(12), 3421-3435.

Bradley, K. E., Feng, L., Hill, E. M., Natawidjaja, D., \& Sieh, K. ～(2017). Implications of the diffuse deformation of the Indian Ocean lithosphere for slip partitioning of oblique plate convergence in Sumatra. Journal of Geophysical Research: Solid Earth, 122(1), 572-591.

Burgette, R. J., Weldon, R. J., II, \& Schmidt, D. A. (2009). Interseismic uplift rates for western Oregon and along-strike variation in locking on the Cascadia subduction zone. Journal of Geophysical Research, 114(B1), B01408. doi: 10.1029/2008JB005679

Bürgmann, R., Kogan, M. G., Steblov, G. M., Hilley, G., Levin, V. E., \& Apel, E. (2005). Interseismic coupling and asperity distribution along the Kamchatka 
subduction zone. Journal of Geophysical Research, 110. (Type: Journal Article) doi: 10.1029/2005JB003648

Carvajal-Soto, L. A., Ito, T., Protti, M., \& Kimura, H. (2020). Earthquake potential in Costa Rica using three scenarios for the central Costa Rica deformed belt as western boundary of the Panama microplate. Journal of South American Earth Sciences, 97, 102375.

Clark, K., Howarth, J., Litchfield, N., Cochran, U., Turnbull, J., Dowling, L., ... Wolfe, F. (2019). Geological evidence for past large earthquakes and tsunamis along the Hikurangi subduction margin, New Zealand. Marine Geology, 412, $139-172$.

Cocard, M., Kahle, H.-G., Peter, Y., Geiger, A., Veis, G., Felekis, S., ... Billiris, H. (1999). New constraints on the rapid crustal motion of the Aegean region: recent results inferred from GPS measurements (1993-1998) across the West Hellenic Arc, Greece. $\quad$ Earth and Planetary Science Letters, 172(1-2), 39-47. doi: 10.1016/S0012-821X(99)00185-5

Comte, D., \& Pardo, M. (1991). Reappraisal of great historical earthquakes in the northern Chile and southern Peru seismic gaps. Natural Hazards, 4 (1), 23-44. doi: $10.1007 / \mathrm{BF} 00126557$

Correa-Mora, F., DeMets, C., Cabral-Cano, E., Marquez-Azua, B., \& Diaz-Molina, O. (2008). Interplate coupling and transient slip along the subduction interface beneath Oaxaca, Mexico. Geophysical Journal International, 175(1), 269-290.

Dal Zilio, L., Jolivet, R., \& Dinther, Y. (2020). Segmentation of the Main Himalayan Thrust Illuminated by Bayesian Inference of Interseismic Coupling. Geophysical Research Letters, 47(4). doi: 10.1029/2019GL086424

Delano, J. E., Amos, C. B., Loveless, J. P., Rittenour, T. M., Sherrod, B. L., \& Lynch, E. M. (2017). Influence of the megathrust earthquake cycle on upperplate deformation in the Cascadia forearc of Washington State, USA. Geology, 45(11), 1051-1054. doi: 10.1130/G39070.1

DeMets, C., Gordon, R. G., Argus, D., \& Stein, S. (1990). Current plate motions. Geophysical journal international, $101(2), 425-478$.

Dixon, T. H., Jiang, Y., Malservisi, R., McCaffrey, R., Voss, N., Protti, M., \& Gonzalez, V. (2014). Earthquake and tsunami forecasts: Relation of slow slip events to subsequent earthquake rupture. Proceedings of the National Academy 
of Sciences, 111(48), 17039-17044.

Dolan, J. F., Mullins, H. T., \& Wald, D. J. (1998). Active tectonics of the northcentral Caribbean: Oblique collision, strain partitioning, and opposing subducted slabs. In Active Strike-Slip and Collisional Tectonics of the Northern Caribbean Plate Boundary Zone. Geological Society of America. doi: $10.1130 / 0-8137-2326-4.1$

Doser, D. I., \& Webb, T. H. (2003). Source parameters of large historical (19171961) earthquakes, North Island, New Zealand. Geophysical journal international, 152(3), 795-832.

Elliott, J., \& Freymueller, J. T. (2020). A Block Model of Present-Day Kinematics of Alaska and Western Canada. Journal of Geophysical Research: Solid Earth, 125(7). doi: 10.1029/2019JB018378

Ellis, A. P., DeMets, C., Briole, P., Molina, E., Flores, O., Rivera, J., .. Lord, N. (2015). Geodetic slip solutions for the $M_{\mathrm{W}}=7.4$ Champerico (Guatemala) earthquake of 2012 November 7 and its postseismic deformation. Geophysical Journal International, 201(2), 856-868.

England, P., \& Bilham, R. (2015). The Shillong Plateau and the great 1897 Assam earthquake. Tectonics, 34(9), 1792-1812. doi: 10.1002/2015TC003902

Feng, L., Newman, A. V., Protti, M., González, V., Jiang, Y., \& Dixon, T. H. (2012). Active deformation near the nicoya peninsula, northwestern costa rica, between 1996 and 2010: Interseismic megathrust coupling. Journal of Geophysical Research: Solid Earth, 117(B6).

Feuillet, N., Beauducel, F., \& Tapponnier, P. (2011). Tectonic context of moderate to large historical earthquakes in the Lesser Antilles and mechanical coupling with volcanoes. Journal of Geophysical Research, 116(B10), B10308. doi: 10.1029/2011JB008443

Fitch, T. J. (1972). Plate convergence, transcurrent faults, and internal deformation adjacent to southeast Asia and the western Pacific. Journal of Geophysical research, $77(23), 4432-4460$.

Frankel, A., Wirth, E., Marafi, N., Vidale, J., \& Stephenson, W. (2018). Broadband Synthetic Seismograms for Magnitude 9 Earthquakes on the Cascadia Megathrust Based on 3D Simulations and Stochastic Synthetics, Part 1: Methodology and Overall Results.

Bulletin of the Seismological Society of America, 
108(5A), 2347-2369. doi: 10.1785/0120180034

Freymueller, J. T., Woodard, H., Cohen, S. C., Cross, R., Elliott, J., Larsen, C. F., ... Zweck, C. (2013). Active Deformation Processes in Alaska, Based on 15 Years of GPS Measurements. In J. T. Freymueller, P. J. Haeussler, R. L. Wesson, \& G. Ekström (Eds.), Geophysical Monograph Series (pp. 1-42). Washington, D. C: American Geophysical Union. doi: 10.1029/179GM02

Gagnon, K., Chadwell, C. D., \& Norabuena, E. (2005). Measuring the onset of locking in the Peru-Chile trench with GPS and acoustic measurements. $\mathrm{Na}$ ture, 434, 205-208. doi: 10.1038/nature03412

Geirsson, H., LaFemina, P. C., DeMets, C., Hernandez, D. A., Mattioli, G. S., Rogers, R., ... Tenorio, V. (2015). The 2012 August $27 M_{\mathrm{W}} 7.4$ El Salvador earthquake: expression of weak coupling on the Middle America subduction zone. Geophysical Journal International, 202(3), 1677-1689.

Geuzaine, C., \& Remacle, J.-F. (2009). Gmsh: A 3-D finite element mesh generator with built-in pre- and post-processing facilities. International Journal for $\mathrm{Nu}$ merical Methods in Engineering, 79(11), 1309-1331. doi: 10.1002/nme.2579

Goldfinger, C., Nelson, C., \& Johnson, J. ～(2003). Holocene earthquake records from the Cascadia Subduction Zone and northern San Andreas Fault based on precise dating of offshore turbidites. Annual Review of Earth and Planetary Sciences, 31, 555-577. doi: 10.1146/annurev.earth.31.100901.141246

Graham, S. E., DeMets, C., Cabral-Cano, E., Kostoglodov, V., Rousset, B., Walpersdorf, A., ... Salazar-Tlaczani, L. (2015). Slow slip history for the Mexico subduction zone: 2005 through 2011. In Geodynamics of the latin american pacific margin (pp. 3445-3465). Springer.

Graham, S. E., DeMets, C., Cabral-Cano, E., Kostoglodov, V., Walpersdorf, A., Cotte, N., ... Salazar-Tlaczani, L. (2014). GPS constraints on the $M_{w}=7.5$ Ometepec earthquake sequence, southern Mexico: Coseismic and post-seismic deformation. Geophysical Journal International, 199(1), 200-218.

Graham, S. E., Loveless, J. P., \& Meade, B. J. (2018). Global Plate Motions and Earthquake Cycle Effects. Geochemistry, Geophysics, Geosystems, 19(7), 2032-2048. doi: 10.1029/2017GC007391

Hanks, T. C., \& Kanamori, H. (1979). Moment Magnitude Scale. Journal of Geophysical Research, 84(NB5), 2348-2350. 
Hashimoto, C., Noda, A., Sagiya, T., \& Matsu'ura, M. (2009). Interplate seismogenic zones along the Kuril-Japan trench inferred from GPS data inversion. Nature Geoscience, 2, 141-144. doi: 10.1038/ngeo421

Hayes, G. P., Herman, M. W., Barnhart, W. D., Furlong, K. P., Riquelme, S., Benz, H. M., ... Samsonov, S. (2014). Continuing megathrust earthquake potential in Chile after the 2014 Iquique earthquake. Nature, 512(7514), 295-+. doi: 10.1038/Nature13677

Hayes, G. P., Moore, G. L., Portner, D. E., Hearne, M., Flamme, H., Furtney, M., \& Smoczyk, G. M. (2018). Slab2, a comprehensive subduction zone geometry model. Science, 362(6410), 58-61. doi: 10.1126/science.aat4723

Hayes, G. P., Wald, D. J., \& Johnson, R. L. (2012). Slab1.0: A three-dimensional model of global subduction zone geometries. Journal of Geophysical Research, 117, B01302. doi: 10.1029/2011JB008524

Heki, K., \& Mitsui, Y. (2013). Accelerated Pacific Plate subduction following interplate thrust earthquakes at the Japan trench. Earth and Planetary Science Letters, 363, 44-49. doi: 10.1016/j.epsl.2012.12.031

Hough, S. E. (2013). Missing great earthquakes. Journal of Geophysical Research: Solid Earth, 118(3), 1098-1108. doi: 10.1002/jgrb.50083

Hubbard, J., Almeida, R., Foster, A., Sapkota, S. N., Bürgi, P., \& Tapponnier, P. (2016). Structural segmentation controlled the $2015 \mathrm{M}_{\mathrm{w}} 7.8$ Gorkha earthquake rupture in Nepal. Geology, 44(8), 639-642. doi: 10.1130/G38077.1

Hutton, W., DeMets, C., Sanchez, O., Suarez, G., \& Stock, J. (2001). Slip kinematics and dynamics during and after the 1995 October $9 M_{\mathrm{W}}=8.0$ ColimaJalisco earthquake, Mexico, from GPS geodetic constraints. Geophysical Journal International, 146(3), 637-658.

Ihmlé, P. F. (1996). Monte Carlo slip inversion in the frequency domain: Application to the 1992 Nicaragua Slow Earthquake. Geophysical research letters, 23(9), 913-916.

Ishibashi, K. (2020). Ancient and Medieval Events and Recurrence Interval of Great Kanto Earthquakes along the Sagami Trough, Central Japan, as Inferred from Historiographical Seismology. $\quad$ Seismological Research Letters, $91(5)$, 2579-2589. doi: $10.1785 / 0220200073$

Ishii, M., Kiser, E., \& Geist, E. L. $\quad$ (2013). $\quad M_{w} 8.6$ Sumatran earthquake of 11 
April 2012: Rare seaward expression of oblique subduction. Geology, 41(3), $319-322$.

Jiang, Z., Yuan, L., Huang, D., Yang, Z., \& Hassan, A. (2018). Postseismic deformation associated with the $2015 \mathrm{mw} 7.8$ gorkha earthquake, nepal: Investigating ongoing afterslip and constraining crustal rheology. Journal of Asian Earth Sciences, 156, 1-10.

Johnson, J. M., \& Satake, K. (1999). Asperity Distribution of the 1952 Great Kamchatka Earthquake and its Relation to Future Earthquake Potential in Kamchatka. In J. Sauber \& R. Dmowska (Eds.), Seismogenic and Tsunamigenic Processes in Shallow Subduction Zones (pp. 541-553). Basel: Birkhäuser Basel. doi: 10.1007/978-3-0348-8679-6\_8

Kanamori, H., \& Kikuchi, M. (1993). The 1992 Nicaragua earthquake: a slow tsunami earthquake associated with subducted sediments. Nature, 361(6414), 714-716.

Kaneko, Y., Avouac, J. P., \& Lapusta, N. (2010). Towards inferring earthquake patterns from geodetic observations of interseismic coupling. Nature Geoscience, 3, 363-369. doi: 10.1038/ngeo843

Kelleher, J. A. (1972). Rupture zones of large South American earthquakes and some predictions. Journal of Geophysical Research, 77(11), 2087-2103.

Kobayashi, D., LaFemina, P., Geirsson, H., Chichaco, E., Abrego, A. A., Mora, H., \& Camacho, E. (2014). Kinematics of the western Caribbean: Collision of the Cocos Ridge and upper plate deformation. Geochemistry, Geophysics, Geosystems, 15(5), 1671-1683.

Kodaira, S., Hori, T., Ito, A., Miura, S., Fujie, G., Park, J.-O., ... Kaneda, Y. (2006). A cause of rupture segmentation and synchronization in the Nankai trough revealed by seismic imaging and numerical simulation. Journal of Geophysical Research, 111, B09301. doi: 10.1029/2005JB004030

Kozdon, J. E., \& Dunham, E. M. (2013). Rupture to the Trench: Dynamic Rupture Simulations of the 11 March 2011 Tohoku Earthquake. Bulletin of the Seismological Society of America, 103(2B), 1275-1289. doi: 10.1785/0120120136

Kreemer, C., Blewitt, G., \& Klein, E. C. (2014). A geodetic plate motion and Global Strain Rate Model. Geochemistry, Geophysics, Geosystems, 15(10), 3849-3889. doi: 10.1002/2014GC005407 
Lave, J., Yule, D., Sapkota, S., Basant, K., Madden, C., Attal, M., \& Pandey, R (2005). Evidence for a great medieval earthquake (approximate to $1100 \mathrm{AD}$ ) in the Central Himalayas, Nepal. Science, 307(5713), 1302-1305.

Lay, T., Kanamori, H., Ammon, C. J., Koper, K. D., Hutko, A. R., Ye, L., .. Rushing, T. M. (2012). Depth-varying rupture properties of subduction zone megathrust faults. Journal of Geophysical Research: Solid Earth, 117(B4).

Le Roux-Mallouf, R., Ferry, M., Cattin, R., Ritz, J.-F., Drukpa, D., \& Pelgay, P. (2020). A 2600-yr-long paleoseismic record for the Himalayan Main Frontal Thrust (Western Bhutan). Solid Earth, 2359-2375. doi: 10.5194/se-2020-59

Li, S., Tao, T., Gao, F., Qu, X., Zhu, Y., Huang, J., \& Wang, Q. (2020). Interseismic Coupling beneath the Sikkim-Bhutan Himalaya Constrained by GPS Measurements and Its Implication for Strain Segmentation and Seismic Activity. Remote Sensing, 12(14), 2202. doi: 10.3390/rs12142202

Loveless, J. P., \& Meade, B. J. (2010). Geodetic imaging of plate motions, slip rates, and partitioning of deformation in Japan. Journal of Geophysical Research, 115, B02410. doi: 10.1029/2008JB006248

Loveless, J. P., \& Meade, B. J. (2011). Spatial correlation of interseismic coupling and coseismic rupture extent of the $2011 \mathrm{MW}=9.0$ Tohoku-oki earthquake. Geophysical Research Letters, 38(17), L17306. doi: 10.1029/2011GL048561

Loveless, J. P., \& Meade, B. J. (2015). Kinematic Barrier Constraints on the Magnitudes of Additional Great Earthquakes Off the East Coast of Japan. Seismological Research Letters, 86(1), 202-209. doi: 10.1785/0220140083

Loveless, J. P., Scott, C. P., Allmendinger, R. W., \& González, G. (2016). Slip distribution of the $2014 M w=8.1$ Pisagua, northern Chile, earthquake sequence estimated from coseismic fore-arc surface cracks. Geophysical Research Letters, 43(19), 10,134-10,141. doi: 10.1002/2016GL070284

Manaker, D. M., Calais, E., Freed, A. M., Ali, S. T., Przybylski, P., Mattioli, G., ... de Chabalier, J. B. (2008). Interseismic Plate coupling and strain partitioning in the Northeastern Caribbean. Geophysical Journal International, 174(3), 889-903. doi: 10.1111/j.1365-246X.2008.03819.x

Mavrommatis, A. P., Segall, P., \& Johnson, K. M. (2014). $\quad$ A decadal-scale deformation transient prior to the $2011 \mathrm{Mw} 9.0$ Tohoku-oki earthquake. Geophysical Research Letters, 41(13), 4486-4494. doi: 10.1002/2014GL060139 
McCaffrey, R. (1992). Oblique plate convergence, slip vectors, and forearc deformation. Journal of Geophysical Research: Solid Earth, 97(B6), 8905-8915.

McCaffrey, R. (1996). Slip partitioning at convergent plate boundaries of SE Asia. Geological Society, London, Special Publications, 106(1), 3-18.

McCaffrey, R. (2002). Crustal block rotations and plate coupling. In S. Stein \& J. T. Freymueller (Eds.), Plate Boundary Zones (Vol. 30, pp. 101-122). American Geophysical Union. doi: 10.1029/030GD06

McCaffrey, R., Long, M., Goldfinger, C., Zwick, P. C., Nabalek, J. L., Johnson, C. K., \& Smith, C. (2000). Rotation and plate locking at the southern Cascadia subduction zone. Geophysical Research Letters, 27, 3117-3120. doi: 10.1029/2000GL011768

McCaffrey, R., Qamar, A., King, R., Wells, R., Khazaradze, G., Williams, C., ... Zwick, P. (2007). Fault locking, block rotation and crustal deformation in the Pacific Northwest. Geophysical Journal International, 169(3), 1315-1340. doi: 10.1111/j.1365-246X.2007.03371.x

McCann, W. R., Nishenko, S. P., Sykes, L. R., \& Krause, J. (1979). Seismic gaps and plate tectonics: Seismic potential for major boundaries. Pure and Applied Geophysics, 117(6), 1082-1147. doi: 10.1007/BF00876211

McClusky, S., Balassanian, S., Barka, A., Demir, C., Ergintav, S., Georgiev, I., ... Veis, G. (2000). Global Positioning System constraints on plate kinematics and dynamics in the eastern Mediterranean and Caucasus. Journal of Geophysical Research, 105(B3), 5695-5719.

Meade, B. J., \& Loveless, J. P. (2009). Block modeling with connected fault network geometries and a linear elastic coupling estimator in spherical coordinates. Bulletin of the Seismological Society of America, 99(6), 3124-3139. doi: $10.1785 / 0120090088$

Michel, S., Gualandi, A., \& Avouac, J.-P. (2019). Interseismic Coupling and Slow Slip Events on the Cascadia Megathrust. Pure and Applied Geophysics, 176 (9), 3867-3891. doi: 10.1007/s00024-018-1991-x

Moreno, M., Rosenau, M., \& Oncken, O. (2010). 2010 Maule earthquake slip correlates with pre-seismic locking of Andean subduction zone. Nature, 467, 198202. doi: $10.1038 /$ nature09349

Murotani, S., Satake, K., \& Fujii, Y. ～(2013). S Scaling relations of seismic mo- 
ment, rupture area, average slip, and asperity size for $M \sim 9$ subductionzone earthquakes. Geophysical Research Letters, 40(19), 5070-5074. doi: $10.1002 /$ grl.50976

Murray, M. H., \& Segall, P. (2001). Modeling broadscale deformation in northern California and Nevada from plate motions and elastic strain accumulation. Geophysical Research Letters, 28(22), 4315-4318.

Natawidjaja, D. H., Bradley, K., Daryono, M. R., Aribowo, S., \& Herrin, J. (2017). Late quaternary eruption of the Ranau Caldera and new geological slip rates of the Sumatran Fault Zone in Southern Sumatra, Indonesia. Geoscience Letters, $4(1), 21$.

Nishimura, T., Hirasawa, T., Miyazaki, S., Sagiya, T., Tada, T., Miura, S., \& Tanaka, K. (2004). Temporal change of interplate coupling in northeastern Japan during 1995-2002 estimated from continuous GPS observations. Geophysical Journal International, 157(2), 901-916. doi: 10.1111/ j.1365-246X.2004.02159.x

Philibosian, B., \& Meltzner, A. J. (2020). Segmentation and supercycles: A catalog of earthquake rupture patterns from the Sumatran Sunda Megathrust and other well-studied faults worldwide. Quaternary Science Reviews, 241, 106390. doi: 10.1016/j.quascirev.2020.106390

Plesch, A., Shaw, J., Benson, C., Bryant, W., Carena, S., Cooke, M., ... others (2007). Community Fault Model (CFM) for Southern California. Bulletin of the Seismological Society of America, 97(6), 1793-1802. doi: $10.1785 / 0120050211$

Plescia, S. M., \& Hayes, G. P. (2020). Geometric controls on megathrust earthquakes. Geophysical Journal International, 222(2), 1270-1282. doi: 10.1093/ gji/ggaa254

Ponraj, M., Miura, S., Reddy, C. D., Amirtharaj, S., \& Mahajan, S. H. (2011). Slip distribution beneath the Central and Western Himalaya inferred from GPS observations: Slip distribution beneath the Himalaya. Geophysical Journal International, 185(2), 724-736. doi: 10.1111/j.1365-246X.2011.04958.x

Protti, M., Gonzalez, V., Newman, A. V., Dixon, T. H., Schwartz, S. Y., Marshall, J. S., .. Owen, S. E. (2014). Nicoya earthquake rupture anticipated by geodetic measurement of the locked plate interface. $\quad$ Nature Geoscience, 7(2), 
117-121. doi: 10.1038/ngeo2038

Radiguet, M., Cotton, F., Vergnolle, M., Campillo, M., Walpersdorf, A., Cotte, N., \& Kostoglodov, V. (2012). Slow slip events and strain accumulation in the Guerrero gap, Mexico. Journal of Geophysical Research: Solid Earth, 117(B4), n/a-n/a. doi: 10.1029/2011JB008801

Reilinger, R., McClusky, S., Paradissis, D., Ergintav, S., \& Vernant, P.

(2010) Geodetic constraints on the tectonic evolution of the Aegean region and strain accumulation along the Hellenic subduction zone. Tectonophysics, 488(1-4), 22-30. doi: $10.1016 /$ j.tecto.2009.05.027

Rousset, B., Campillo, M., Lasserre, C., Frank, W. B., Cotte, N., Walpersdorf, A., ... Kostoglodov, V. (2017). A geodetic matched filter search for slow slip with application to the Mexico subduction zone. Journal of Geophysical Research: Solid Earth, 122(12), 10-498.

Satake, K. (1994). Mechanism of the 1992 Nicaragua tsunami earthquake. Geophysical Research Letters, 21(23), 2519-2522.

Satake, K. (2015). Geological and historical evidence of irregular recurrent earthquakes in Japan. Philosophical Transactions of the Royal Society A: Mathematical, Physical and Engineering Sciences, 373(2053), $20140375 . \quad$ doi: $10.1098 /$ rsta.2014.0375

Schmalzle, G. M., McCaffrey, R., \& Creager, K. C. (2014). Central Cascadia subduction zone creep. Geochemistry, Geophysics, Geosystems, 15(4), 1515-1532. doi: 10.1002/2013GC005172

Sella, G. F., Dixon, T. H., \& Mao, A. (2002). Revel: A model for recent plate velocities from space geodesy. Journal of Geophysical Research: Solid Earth, 107(B4), ETG-11.

Shrivastava, M. N., González, G., Moreno, M., Chlieh, M., Salazar, P., Reddy, C., ... de la Llera, J. C. (2016). Coseismic slip and afterslip of the $2015 \mathrm{Mw} 8.3$ Illapel (Chile) earthquake determined from continuous GPS data. Geophysical Research Letters, 43(20), 10-710.

Sieh, K. (1996). The repetition of large-earthquake ruptures. Proceedings of the National Academy of Sciences, 93(9), 3764-3771.

Singh, S., Ponce, L., \& Nishenko, S. (1985). The great Jalisco, Mexico, earthquakes of 1932: Subduction of the Rivera plate. Bulletin of the Seismological Society 
of America, 75 (5), 1301-1313.

Stevens, V. L., \& Avouac, J. P. (2015). Interseismic coupling on the main Himalayan thrust. Geophysical Research Letters, 42(14), 5828-5837. doi 10.1002/2015GL064845

Suárez, G., Monfret, T., Wittlinger, G., \& David, C. (1990). Geometry of subduction and depth of the seismogenic zone in the Guerrero gap, Mexico. Nature, 345(6273), 336-338.

Sykes, L. R., McCann, W. R., \& Kafka, A. L. (1982). Motion of Caribbean Plate during last 7 million years and implications for earlier Cenozoic movements. Journal of Geophysical Research: Solid Earth, 87(B13), 10656-10676. doi: 10.1029/JB087iB13p10656

Symithe, S., Calais, E., de Chabalier, J. B., Robertson, R., \& Higgins, M. Current block motions and strain accumulation on active faults in the Caribbean. Journal of Geophysical Research: Solid Earth, 120(5), 3748-3774. doi: 10.1002/2014JB011779

ten Brink, U. S., Bakun, W. H., \& Flores, C. H. (2011). Historical perspective on seismic hazard to Hispaniola and the northeast Caribbean region. Journal of Geophysical Research, 116(B12), B12318. doi: 10.1029/2011JB008497

USGS Earthquake Catalog Search. (2021). Retrieved 17/2/2021, from https:// earthquake.usgs.gov/earthquakes/search/

Utsu, T. (2004). Catalog of Damaging Earthquakes in the World (Through 2015). Retrieved from https://iisee.kenken.go.jp/utsu/index_eng.html

Vernant, P., Reilinger, R., \& McClusky, S. (2014). Geodetic evidence for low coupling on the Hellenic subduction plate interface. Earth and Planetary Science Letters, 385, 122-129. doi: 10.1016/j.epsl.2013.10.018

Wallace, L. M., Barnes, P., Beavan, J., Van Dissen, R., Litchfield, N., Mountjoy, J., ... Pondard, N. (2012). The kinematics of a transition from subduction to strike-slip: An example from the central New Zealand plate boundary. Journal of Geophysical Research: Solid Earth, 117(B2).

Wallace, L. M., \& Beavan, J. (2006). A large slow slip event on the central Hikurangi subduction interface beneath the Manawatu region, North Island, New Zealand. Geophysical Research Letters, 33(11). 
Wallace, L. M., \& Beavan, J. (2010a). Diverse slow slip behavior at the Hikurangi subduction margin, New Zealand. Journal of Geophysical Research, 115(B12), B12402. doi: 10.1029/2010JB007717

Wallace, L. M., \& Beavan, J. (2010b). Diverse slow slip behavior at the Hikurangi subduction margin, New Zealand. Journal of Geophysical Research: Solid Earth, 115(B12).

Wallace, L. M., Beavan, J., Bannister, S., \& Williams, C. (2012). Simultaneous long-term and short-term slow slip events at the Hikurangi subduction margin, New Zealand: Implications for processes that control slow slip event occurrence, duration, and migration. Journal of Geophysical Research: Solid Earth, 117(B11).

Wallace, L. M., Beavan, J., McCaffrey, R., \& Darby, D. (2004). Subduction zone coupling and tectonic block rotations in the North Island, New Zealand. Journal of Geophysical Research: Solid Earth, 109(B12).

Wallace, L. M., Cochran, U. A., Power, W. L., \& Clark, K. J. (2014). Earthquake and tsunami potential of the Hikurangi subduction thrust, New Zealand: Insights from paleoseismology, GPS, and tsunami modeling. Oceanography, $27(2), 104-117$.

Wallace, L. M., Hreinsdóttir, S., Ellis, S., Hamling, I., D’Anastasio, E., \& Denys, P. (2018). Triggered slow slip and afterslip on the southern Hikurangi subduction zone following the Kaikōura earthquake. Geophysical Research Letters, $45(10)$, $4710-4718$.

Wallace, L. M., Webb, S. C., Ito, Y., Mochizuki, K., Hino, R., Henrys, S., .. Sheehan, A. F. (2016). Slow slip near the trench at the Hikurangi subduction zone, New Zealand. Science, 352(6286), 701-704.

Wang, K., Wells, R., Mazzotti, S., Hyndman, R. D., \& Sagiya, T. $\quad$ (2003). $\quad$ A revised dislocation model of interseismic deformation of the Cascadia subduction zone. Journal of Geophysical Research, 108(B1). (Type: Journal Article) doi: 10.1029/2001JB001227

Webb, T. H., \& Anderson, H. (1998). Focal mechanisms of large earthquakes in the North Island of New Zealand: slip partitioning at an oblique active margin. Geophysical journal international, 134(1), 40-86. 
Wessel, P., Smith, W. H. F., Scharroo, R., Luis, J., \& Wobbe, F. (2013). Generic mapping tools: Improved version released. Eos, Transactions American Geophysical Union, 94(45), 409-410. doi: https://doi.org/10.1002/2013EO450001

White, R. A., Ligorría, J. P., \& Cifuentes, I. L. (2004). Seismic history of the Middle America subduction zone along El Salvador, Guatemala, and Chiapas, Mexico: 1526-2000. SPECIAL PAPERS-GEOLOGICAL SOCIETY OF AMERICA, 379-396.

Wirth, E. A., Frankel, A. D., Marafi, N., Vidale, J. E., \& Stephenson, W. J. (2018). Broadband Synthetic Seismograms for Magnitude 9 Earthquakes on the Cascadia Megathrust Based on 3D Simulations and Stochastic Synthetics, Part 2: Rupture Parameters and Variability. Bulletin of the Seismological Society of America, 108(5A), 2370-2388. doi: 10.1785/0120180029

Wobus, C., Heimsath, A., Whipple, K., \& Hodges, K. (2005). Active out-of-sequence thrust faulting in the central Nepalese Himalaya. Nature, 434(7036), 10081011.

Wobus, C. W., Hodges, K. V., \& Whipple, K. X. (2003). Has focused denudation sustained active thrusting at the Himalayan topographic front? Geology, $31(10), 861-864$.

Yadav, R. K., Gahalaut, V. K., Bansal, A. K., Sati, S., Catherine, J., Gautam, P., ... Rana, N. (2019). Strong seismic coupling underneath Garhwal-Kumaun region, NW Himalaya, India. Earth and Planetary Science Letters, 506, 8-14. doi: $10.1016 /$ j.epsl.2018.10.023

Ye, L., Lay, T., Kanamori, H., \& Rivera, L. (2016). Rupture characteristics of major and great $\left(M_{w} \geq 7.0\right)$ megathrust earthquakes from 1990 to 2015: 1 . Source parameter scaling relationships. Journal of Geophysical Research: Solid Earth, 121 (2), 826-844. doi: 10.1002/2015JB012426

Yokota, Y., Ishikawa, T., Sato, M., Watanabe, S.-i., Saito, H., Ujihara, N., ... Asada, A. (2015). Heterogeneous interplate coupling along the Nankai Trough, Japan, detected by GPS-acoustic seafloor geodetic observation. Progress in Earth and Planetary Science, 2(1). doi: 10.1186/s40645-015-0040-y

Yoshioka, S., Wang, K., \& Mazzotti, S. (2005). Interseismic locking of the plate interface in the northern Cascadia subduction zone, inferred from inversion of GPS data. Earth and Planetary Science Letters, 231(3-4), 239-247. doi: 
10.1016/j.epsl.2004.12.018 

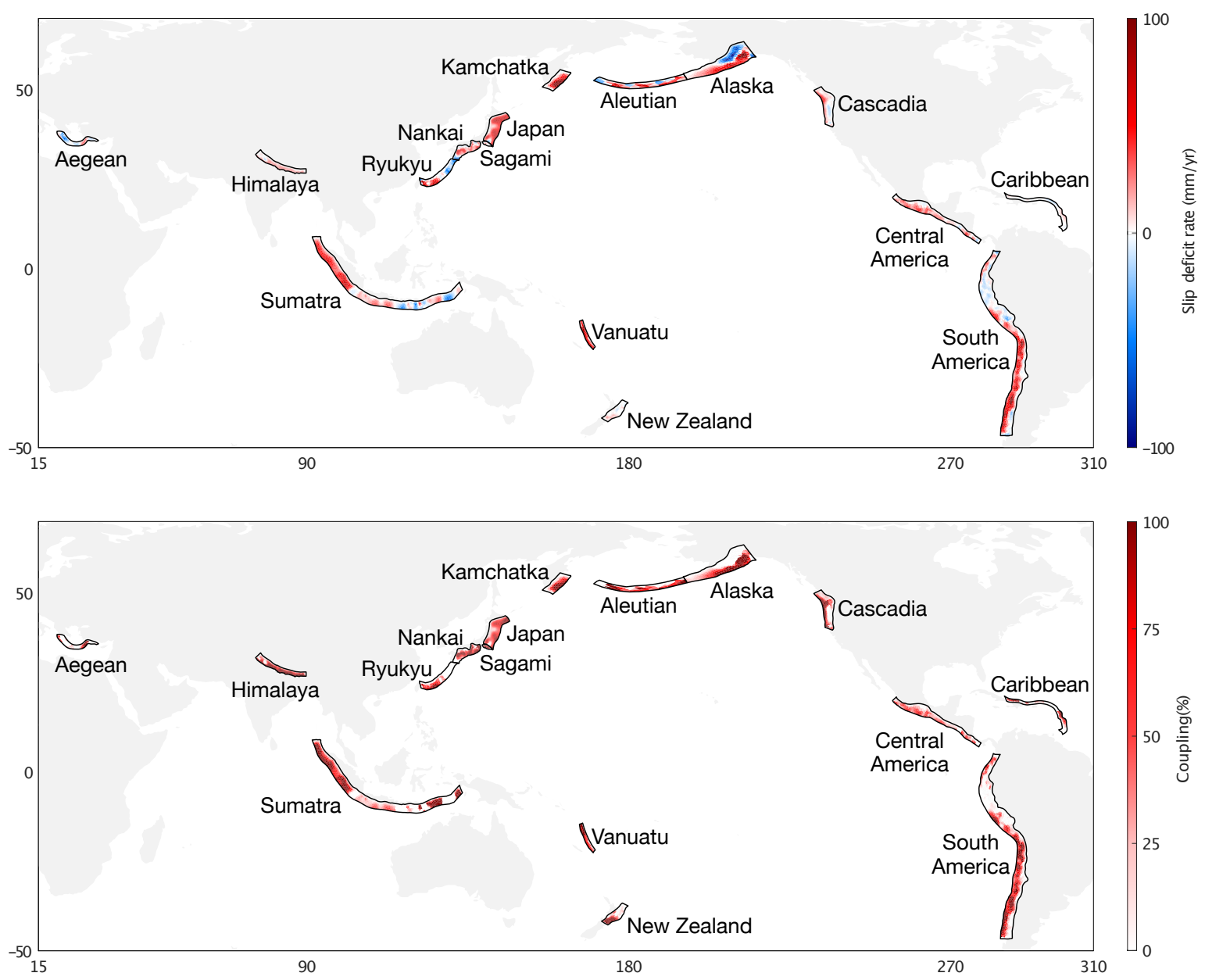

Figure 1. Slip deficit rates (upper panel) and percentage coupling rates for the partially coupled regions in the global block model. The red regions in the upper panel indicate parts of the fault interface where there is partial coupling in the sense that the slip deficit rates are less than the differential plate motion. In contrast blue regions represent slow coseismic sense slip that exceeds the differential plate rates. The red areas in the lower panel are again the lower region are again areas of slip deficit shown as a percentage of the differential plate motion. 


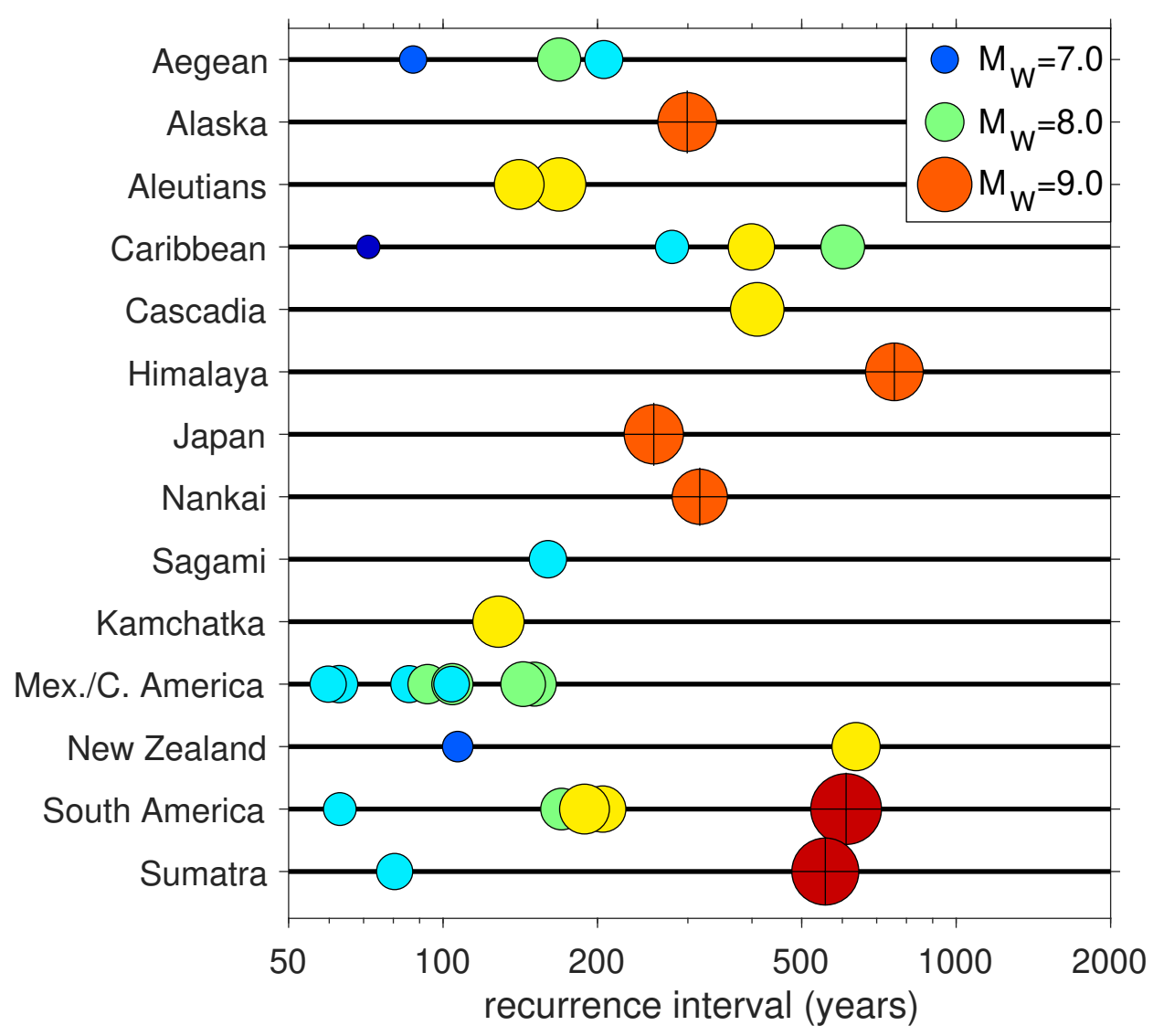

Figure 2. A global subduction zone potential earthquake scenario for the coupling coefficient 0.5 case. The horizontal axis indicates the potential event recurrence interval and the vertical axis indicates the scenarios for individual subduction zones. This scenario features $33 \mathrm{M}_{\mathrm{W}} \geq 7.0$ events including $6 \mathrm{M}_{\mathrm{W}} \geq 9.0$ events. Scenario events $\mathrm{M}_{\mathrm{W}} \geq 9.0$ are indicated with a "+" symbol in the middle of the circle. 


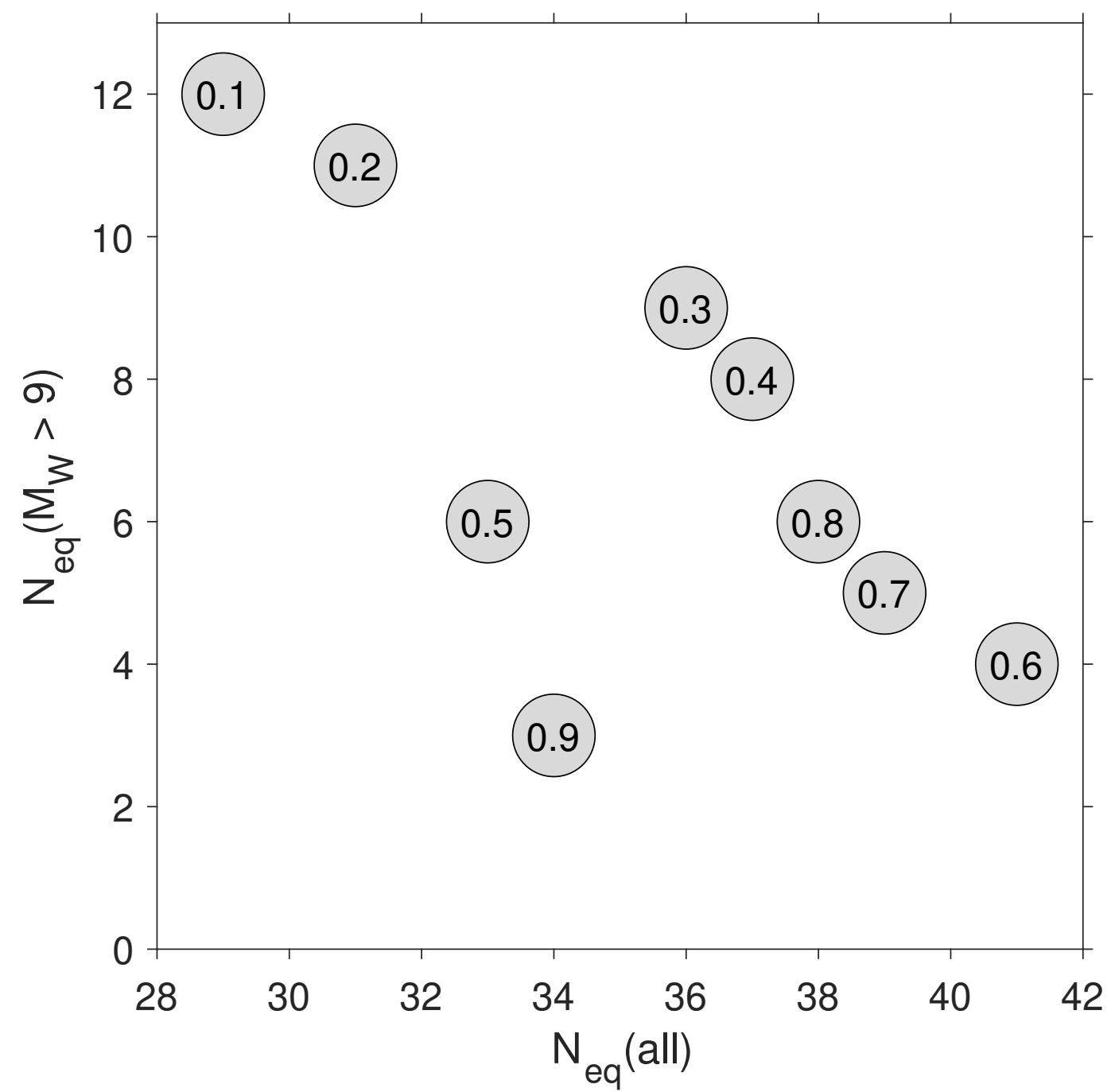

Figure 3. Global number of $\mathrm{M}_{\mathrm{W}} \geq 6.5$ earthquakes, $\mathrm{N}_{\mathrm{eq}}$ (all), versus number of $\mathrm{M}_{\mathrm{W}} \geq 9.0$ earthquakes, $\mathrm{N}_{\mathrm{eq}}\left(\mathrm{M}_{\mathrm{W}}>9\right)$, for global block model scenarios from coupling fractions 0.1-0.9, which label each gray point. 

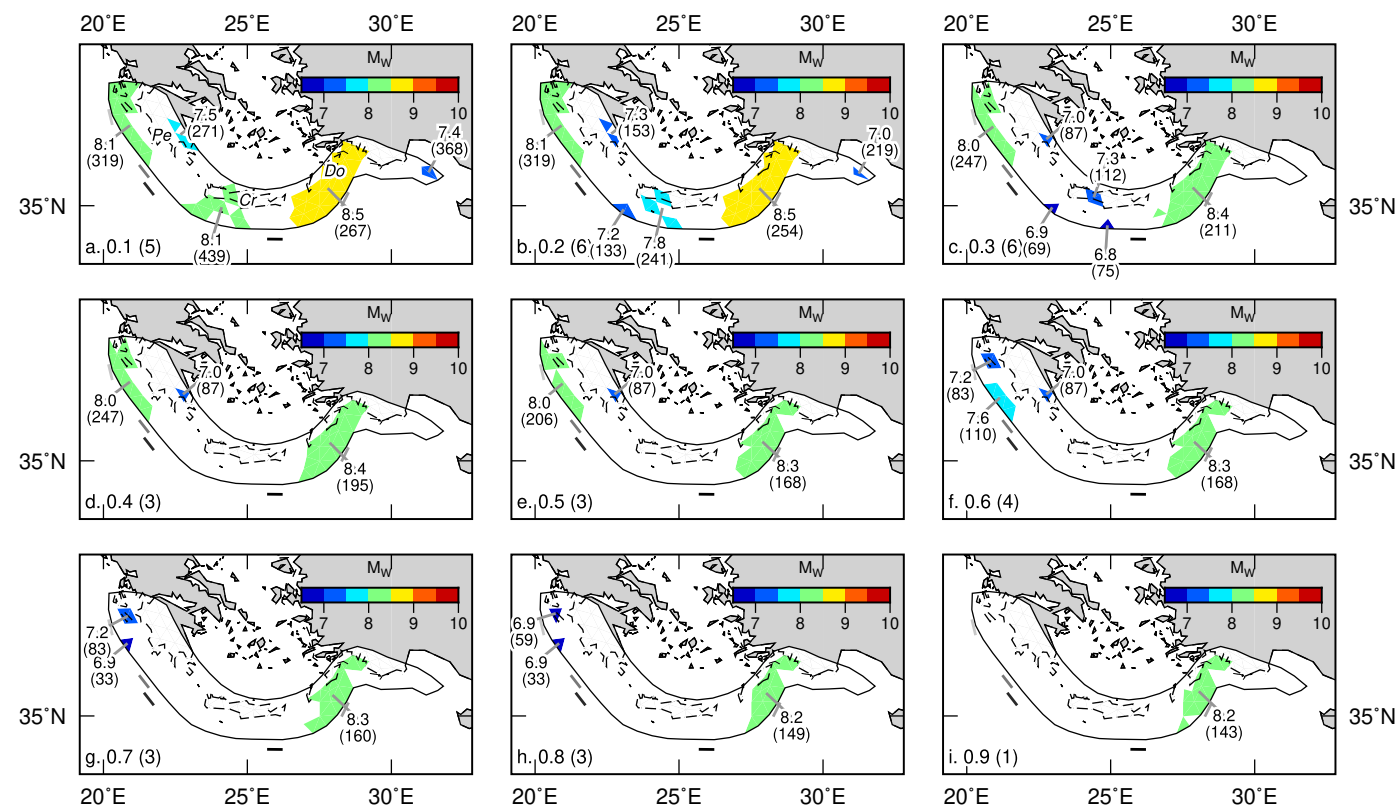

Figure 4. Proposed earthquake rupture areas based on estimated interseismic coupling on the Aegean subduction zone (Hellenic Trench). Each figure panel label indicates a coupling fraction (defined as the ratio of slip deficit rate to relative plate convergence rate, where 0 is freely slipping and 1 is fully coupled), and the number in parentheses gives the number of potential earthquakes defined by clusters of elements coupled at or above this increment. These element clusters are colored based on the potential moment magnitude, defined from an empirical scaling between area and moment magnitude (Allen \& Hayes, 2017). Each cluster is labeled with its moment magnitude and, in parentheses, recurrence interval, which we determine based on the estimated slip deficit rate. Grayscale lines near the trench indicate approximate rupture length of some recent to historical great earthquakes. Abbreviations of place names, in italics, in (a) are Pe: Peleponnese (Peninsula); Cr: Crete; Do: Dodecanese (Islands). 

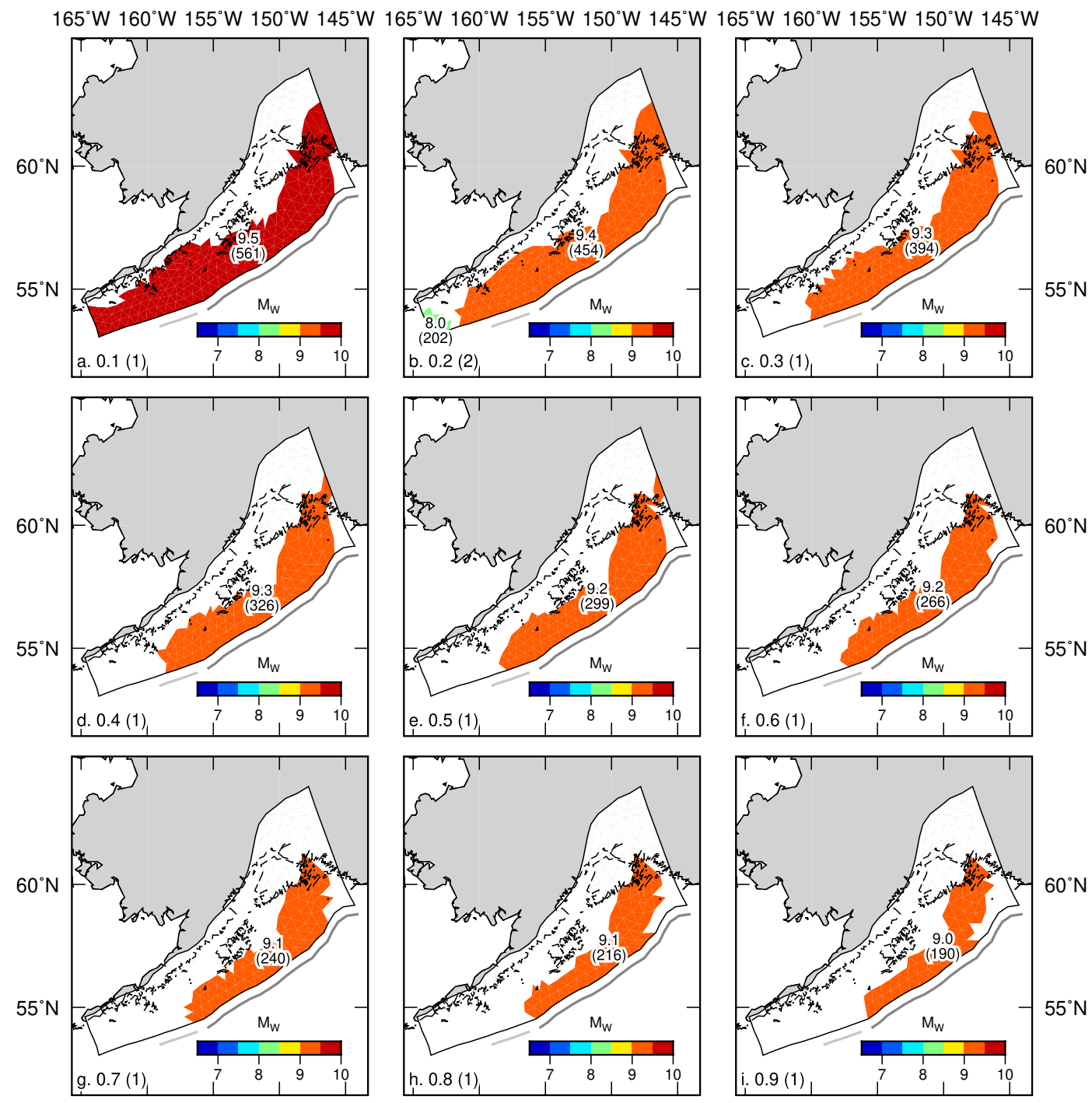

$165^{\circ} \mathrm{W} 160^{\circ} \mathrm{W} 155^{\circ} \mathrm{W} 150^{\circ} \mathrm{W} 145^{\circ} \mathrm{W} 165^{\circ} \mathrm{W} 160^{\circ} \mathrm{W} 155^{\circ} \mathrm{W} 150^{\circ} \mathrm{W} 145^{\circ} \mathrm{W} 165^{\circ} \mathrm{W} 160^{\circ} \mathrm{W} 155^{\circ} \mathrm{W} 150^{\circ} \mathrm{W} 145^{\circ} \mathrm{W}$

Figure 5. Proposed earthquake rupture areas based on estimated interseismic coupling on the Alaska subduction zone, with symbology and annotations as indicated in Figure 4. 

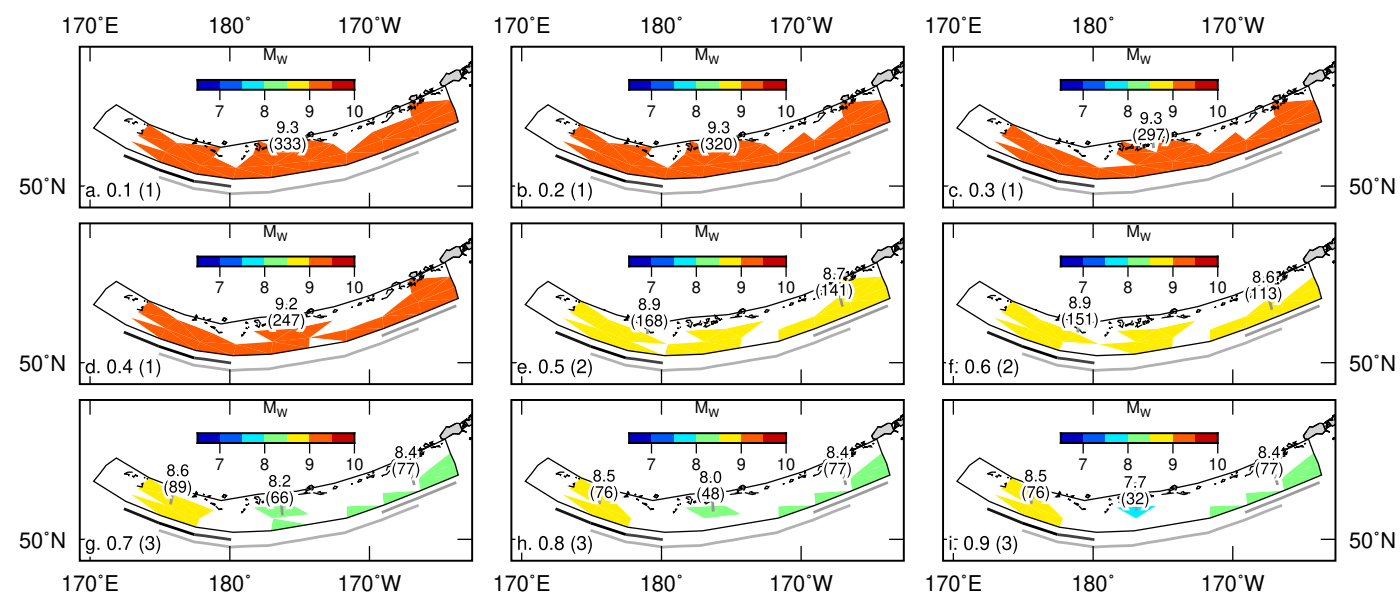

Figure 6. Proposed earthquake rupture areas based on estimated interseismic coupling on the Aleutian Trench, with symbology and annotations as indicated in Figure 4.
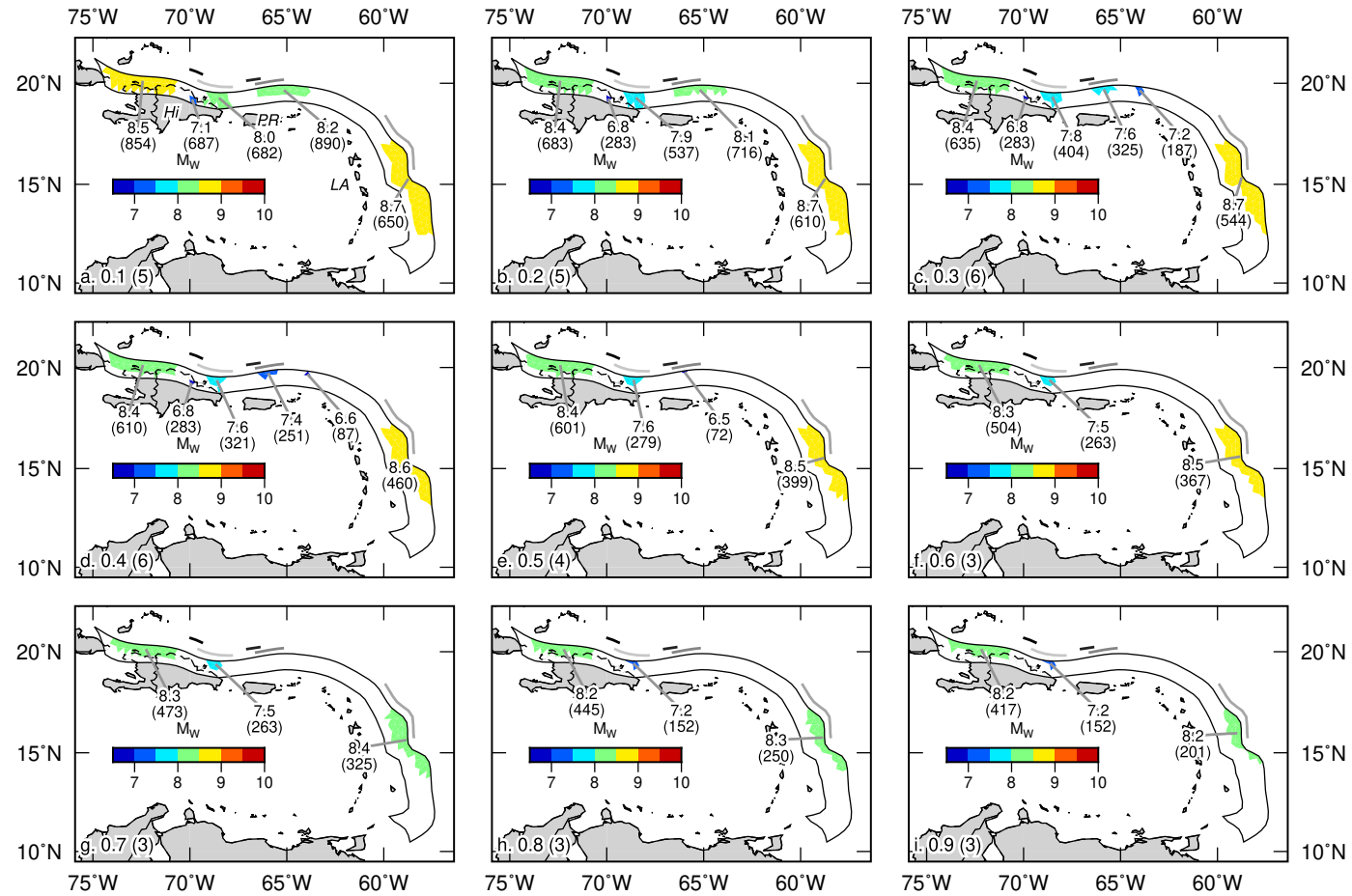

Figure 7. Proposed earthquake rupture areas based on estimated interseismic coupling on the Caribbean subduction zone, with symbology and annotations as indicated in Figure 4. Abbreviations of place names in (a) are Hi: Hispaniola; PR: Puerto Rico; LA: Lesser Antilles. 

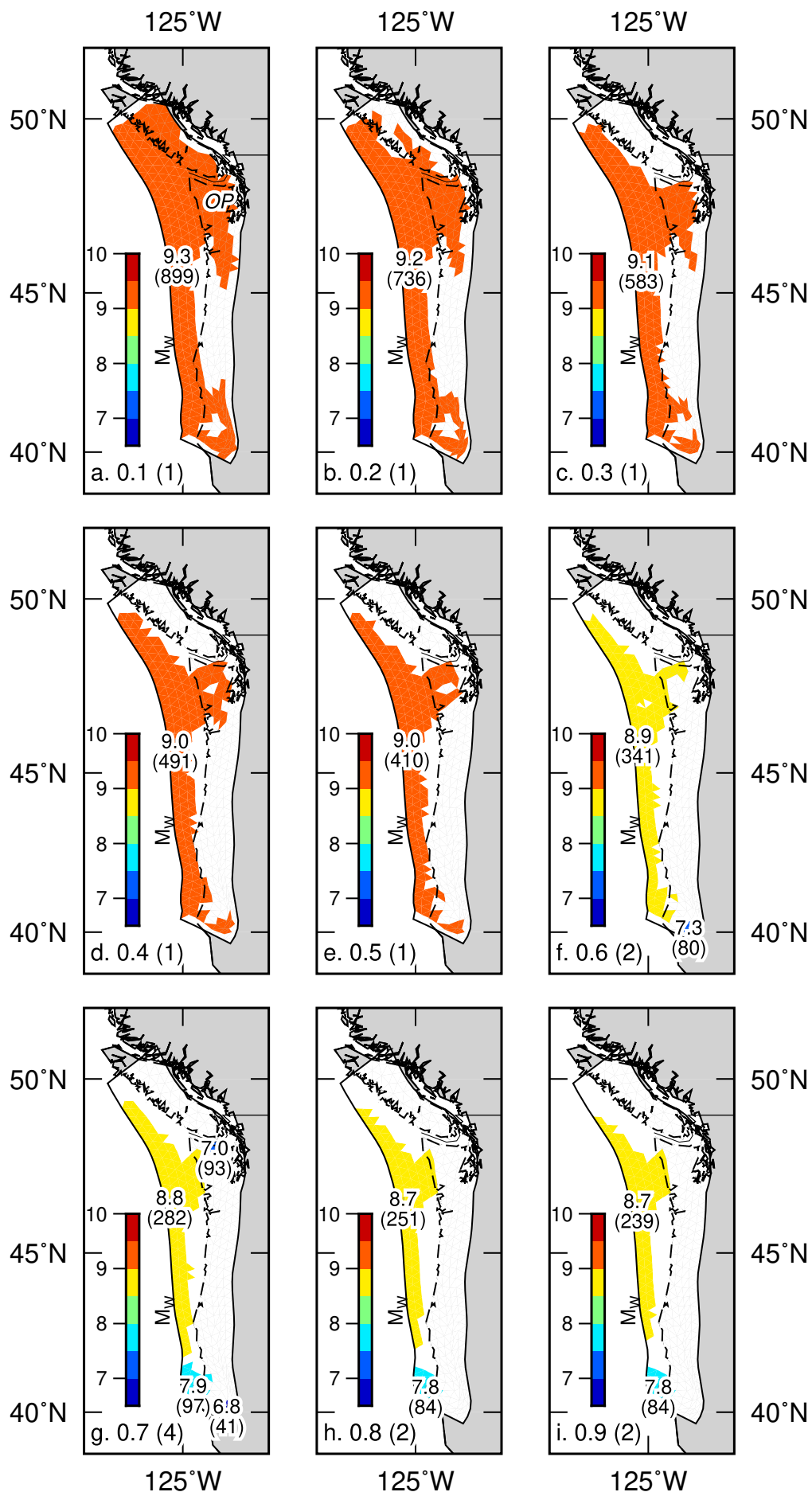

Figure 8. Proposed earthquake rupture areas based on estimated interseismic coupling on the Cascadia subduction zone, with symbology and annotations as indicated in Figure 4. Abbreviations of place name in (a) is OP: Olympic Peninsula. 

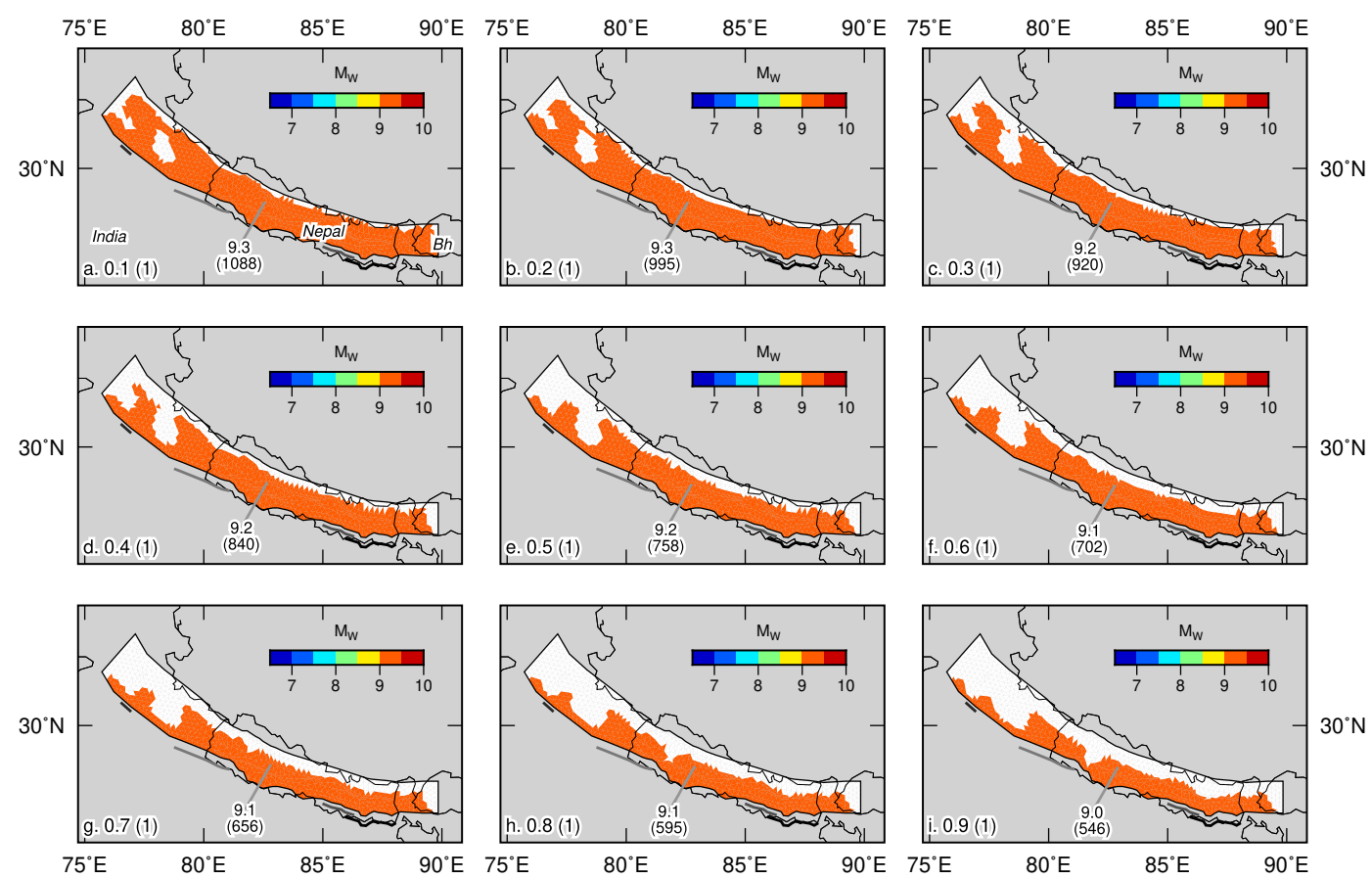

Figure 9. Proposed earthquake rupture areas based on estimated interseismic coupling on the Himalayan Range Front, with symbology and annotations as indicated in Figure 4. Black lines on land are national boundaries, and abbreviation of country name in (a) is Bh: Bhutan. 

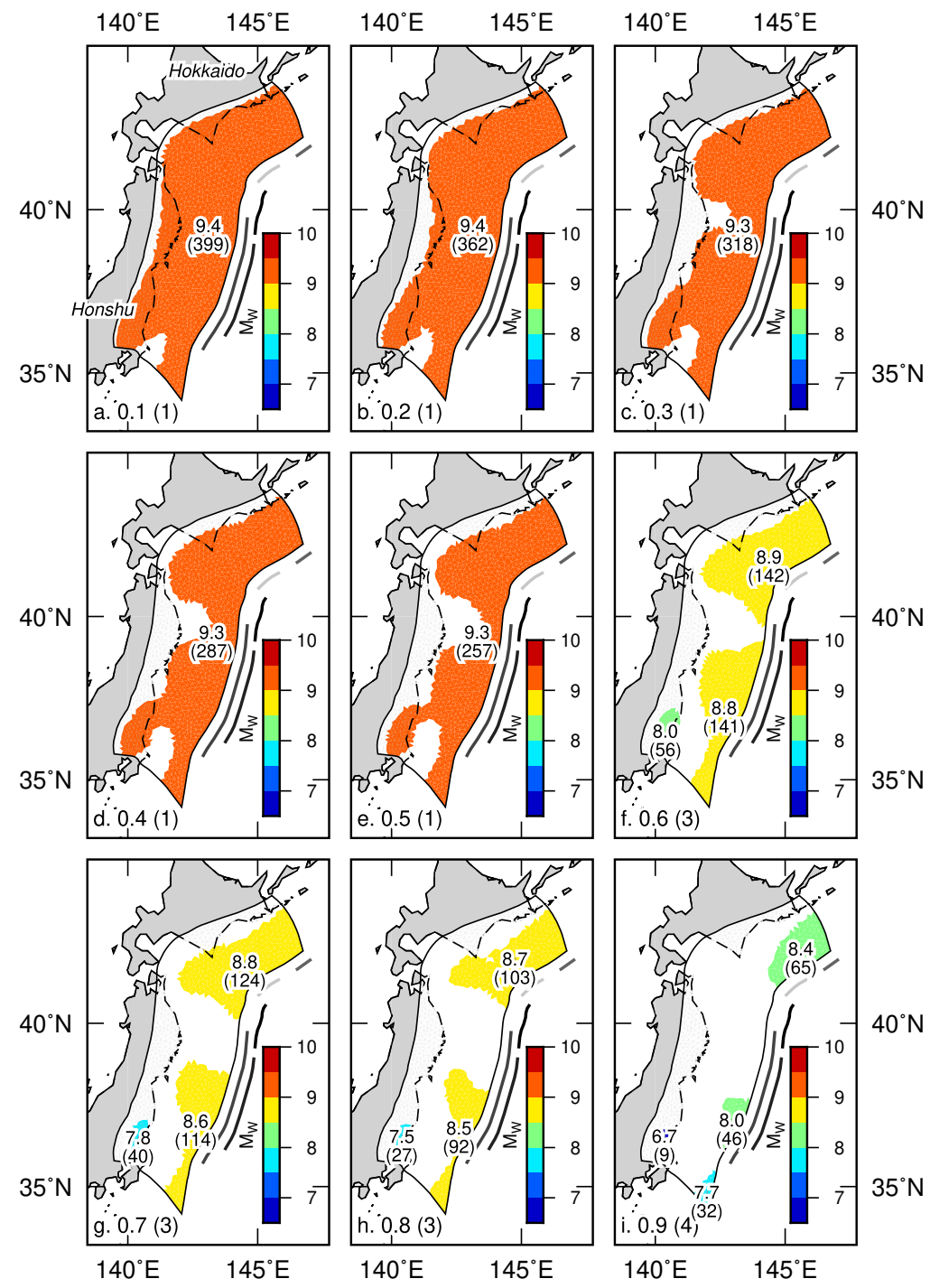

Figure 10. Proposed earthquake rupture areas based on estimated interseismic coupling on the Japan Trench, with symbology and annotations as indicated in Figure 4. 

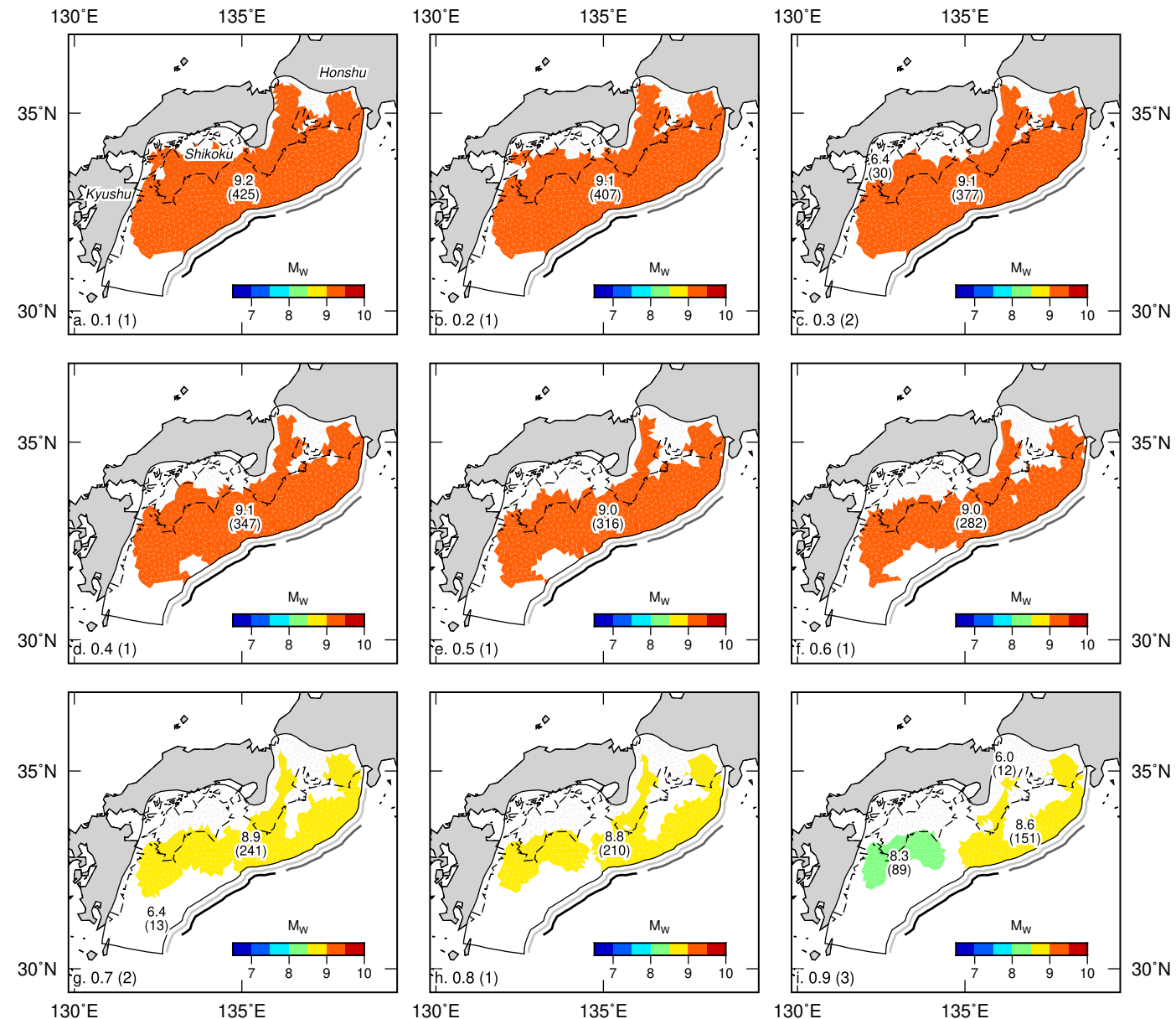

Figure 11. Proposed earthquake rupture areas based on estimated interseismic coupling on the Nankai Trough, with symbology and annotations as indicated in Figure 4. 

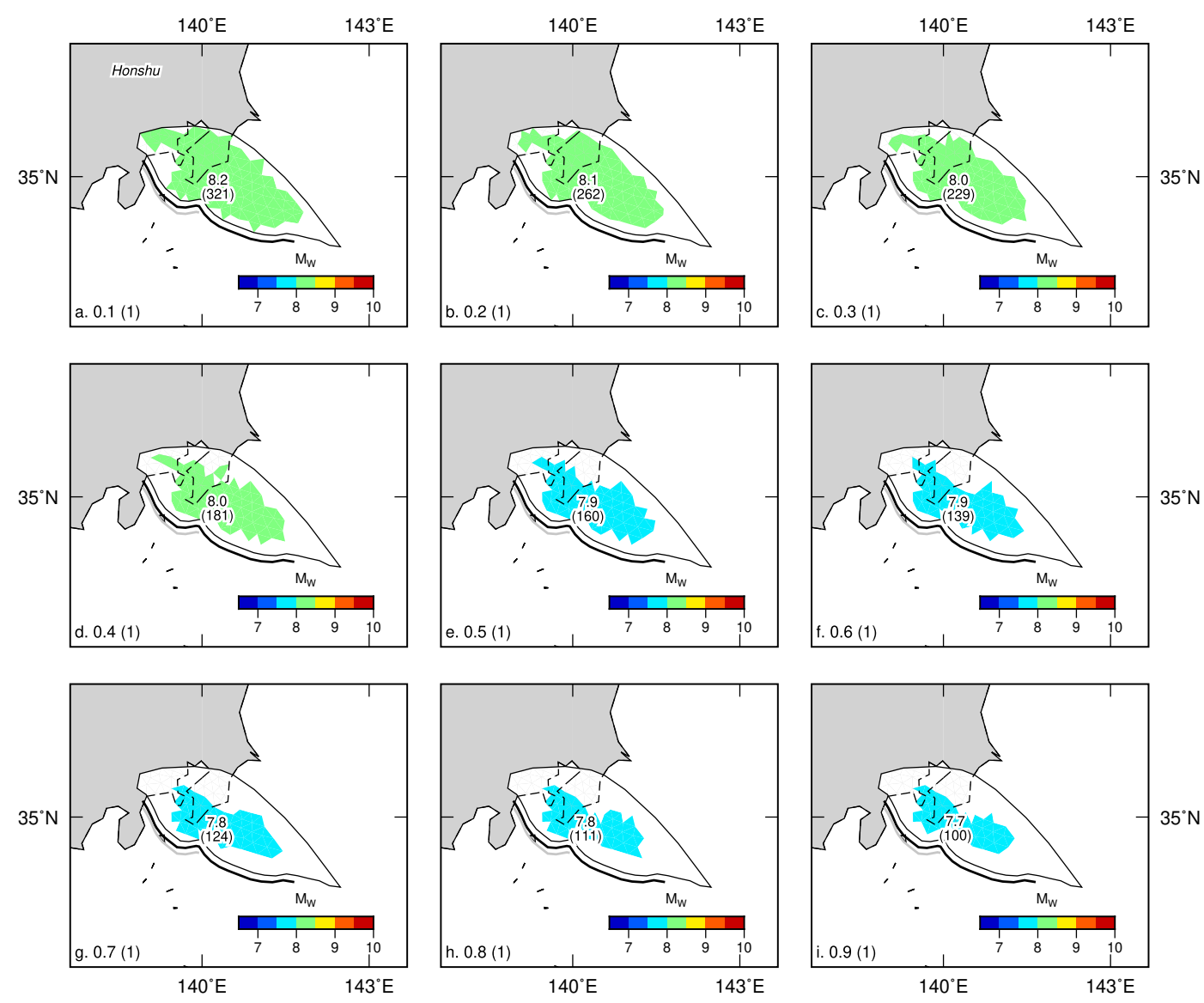

Figure 12. Proposed earthquake rupture areas based on estimated interseismic coupling on the Sagami Trough, with symbology and annotations as indicated in Figure 4. 


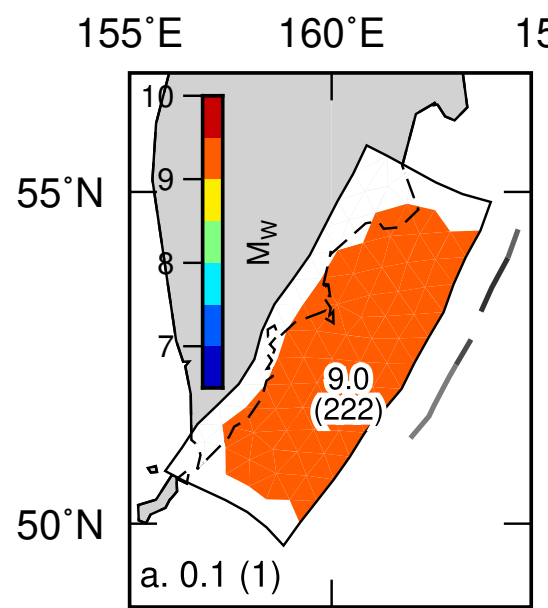

$155^{\circ} \mathrm{E} \quad 160^{\circ} \mathrm{E}$

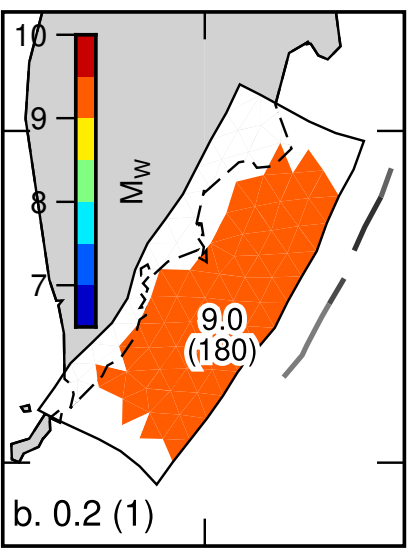

b. 0.2 (1)
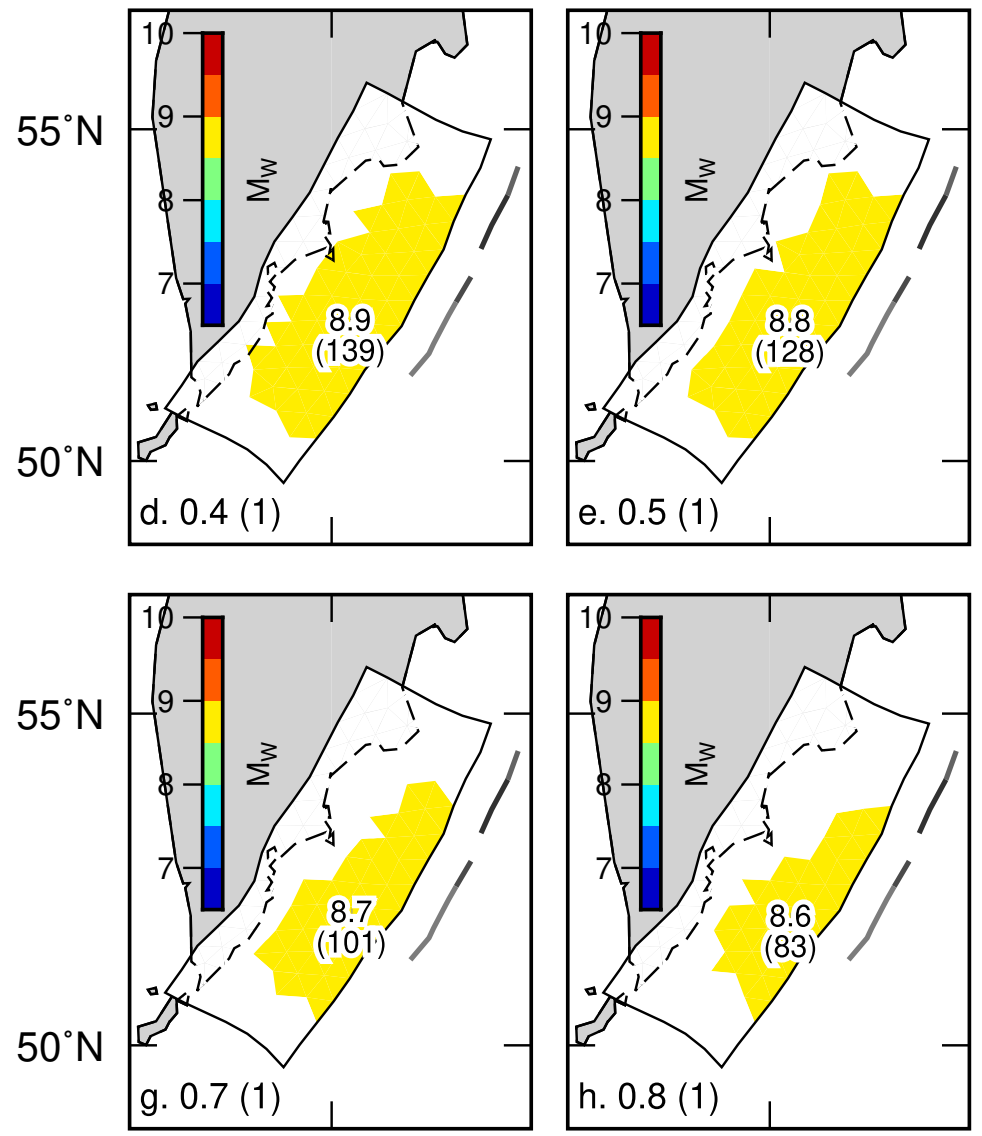

$155^{\circ} \mathrm{E} \quad 160^{\circ} \mathrm{E}$

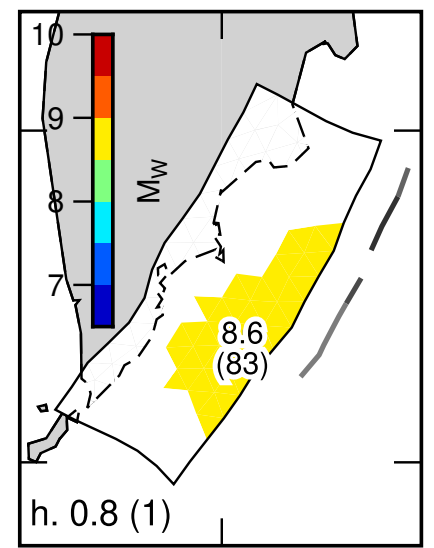

$155^{\circ} \mathrm{E} \quad 160^{\circ} \mathrm{E}$ $155^{\circ} \mathrm{E} \quad 160^{\circ} \mathrm{E}$
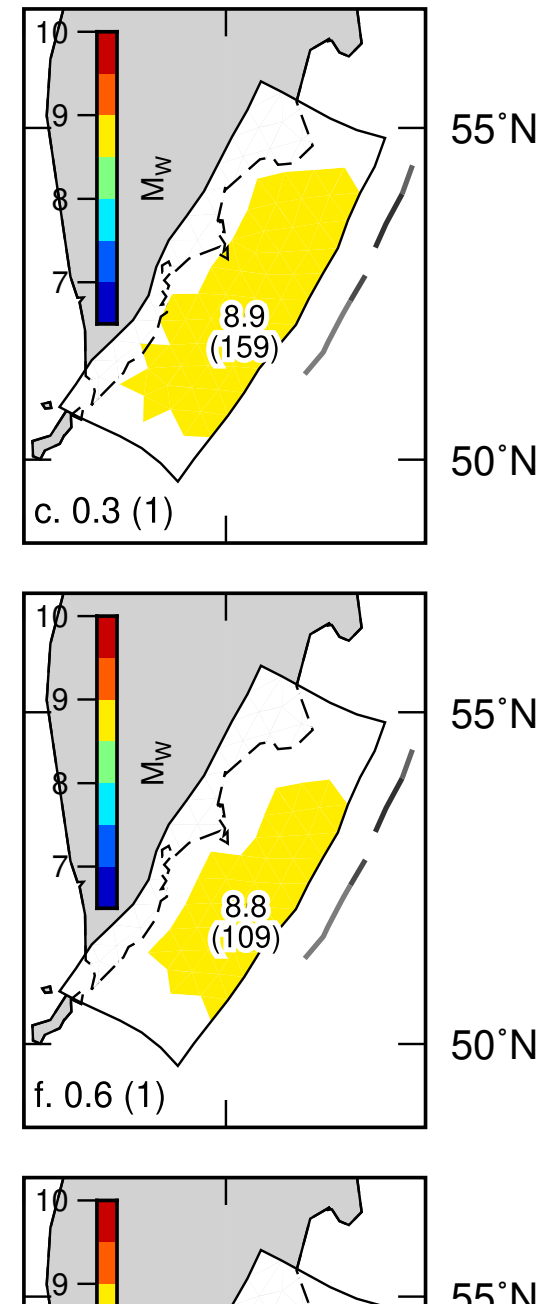

$155^{\circ} \mathrm{E} \quad 160^{\circ} \mathrm{E}$

Figure 13. Proposed earthquake rupture areas based on estimated interseismic coupling on the Kamchatka subduction zone, with symbology and annotations as indicated in Figure 4. 

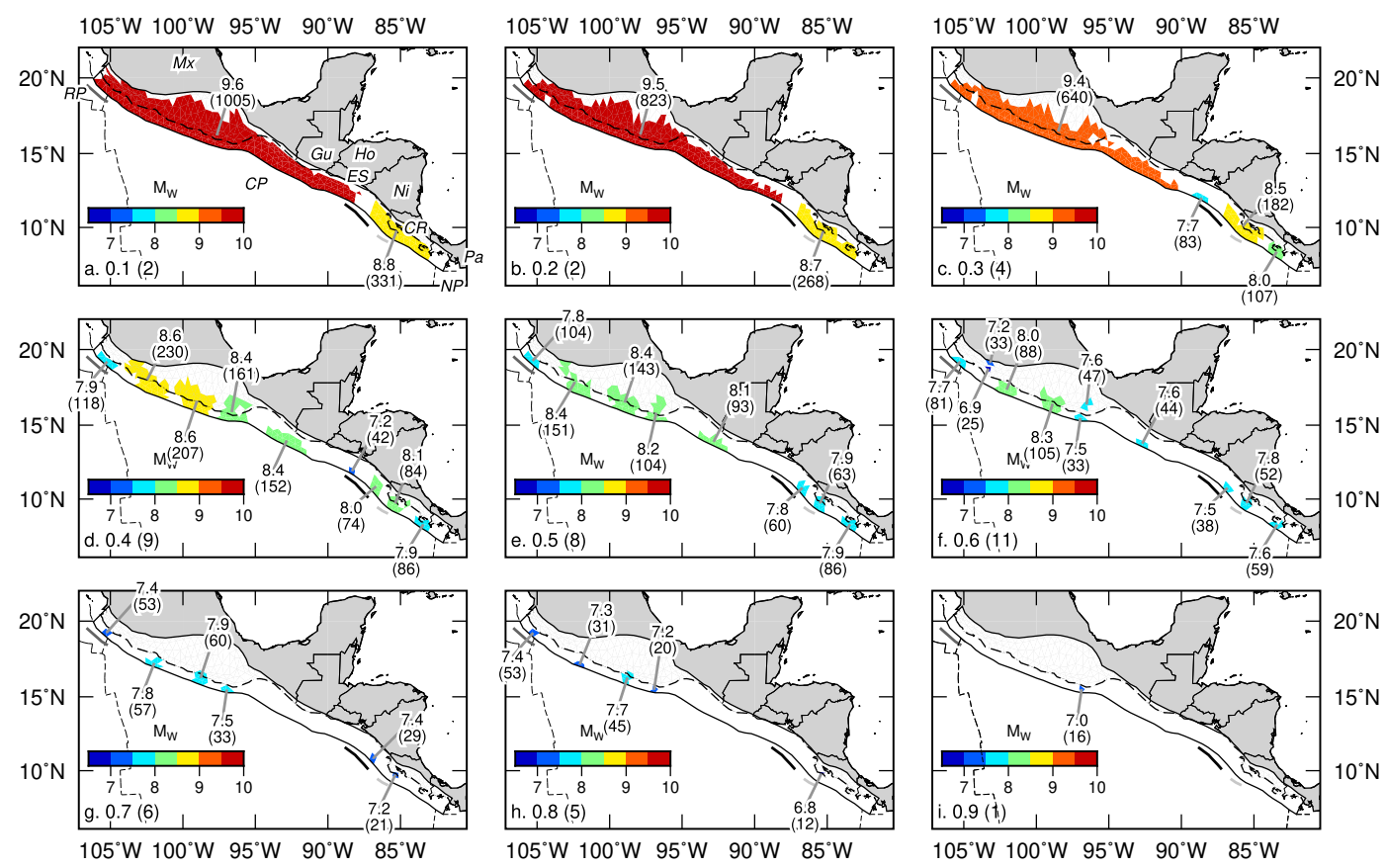

Figure 14. Proposed earthquake rupture areas based on estimated interseismic coupling on the Mexico-Central America subduction zone, with symbology and annotations as indicated in Figure 4. Black lines on land are national boundaries, and abbreviations of country names in (a) are Mx: Mexico; Gu: Guatemala; Ho: Honduras; ES: El Salvador; Ni: Nicaragua; CR: Costa Rica; Pa: Panama. Dashed lines offshore show oceanic plate boundaries mentioned in the text, with abbreviations in (a) of RP: Riviera Plate; CP: Cocos Plate; NP: Nazca Plate. 

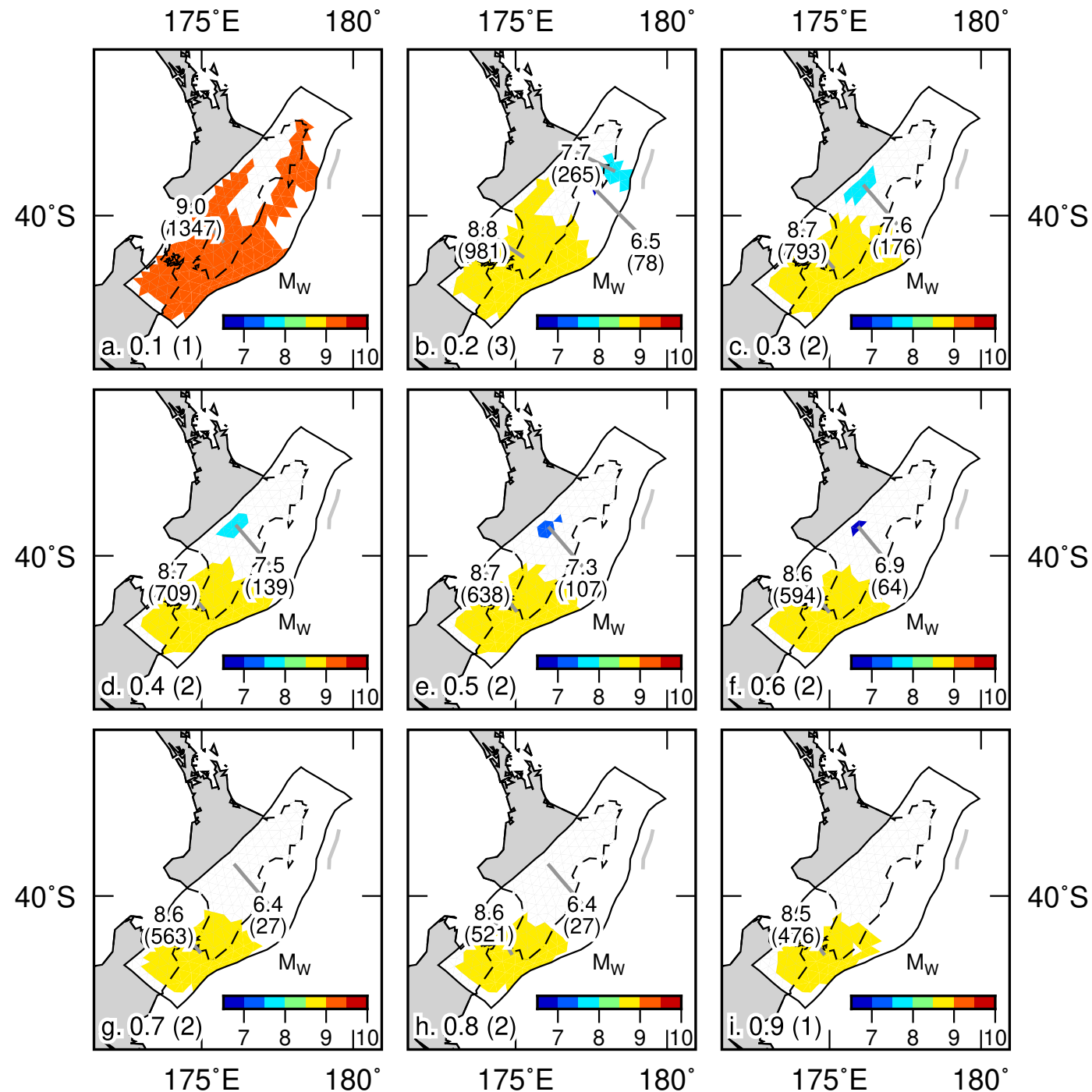

Figure 15. Proposed earthquake rupture areas based on estimated interseismic coupling on the Hikurangi subduction zone, with symbology and annotations as indicated in Figure 4. 


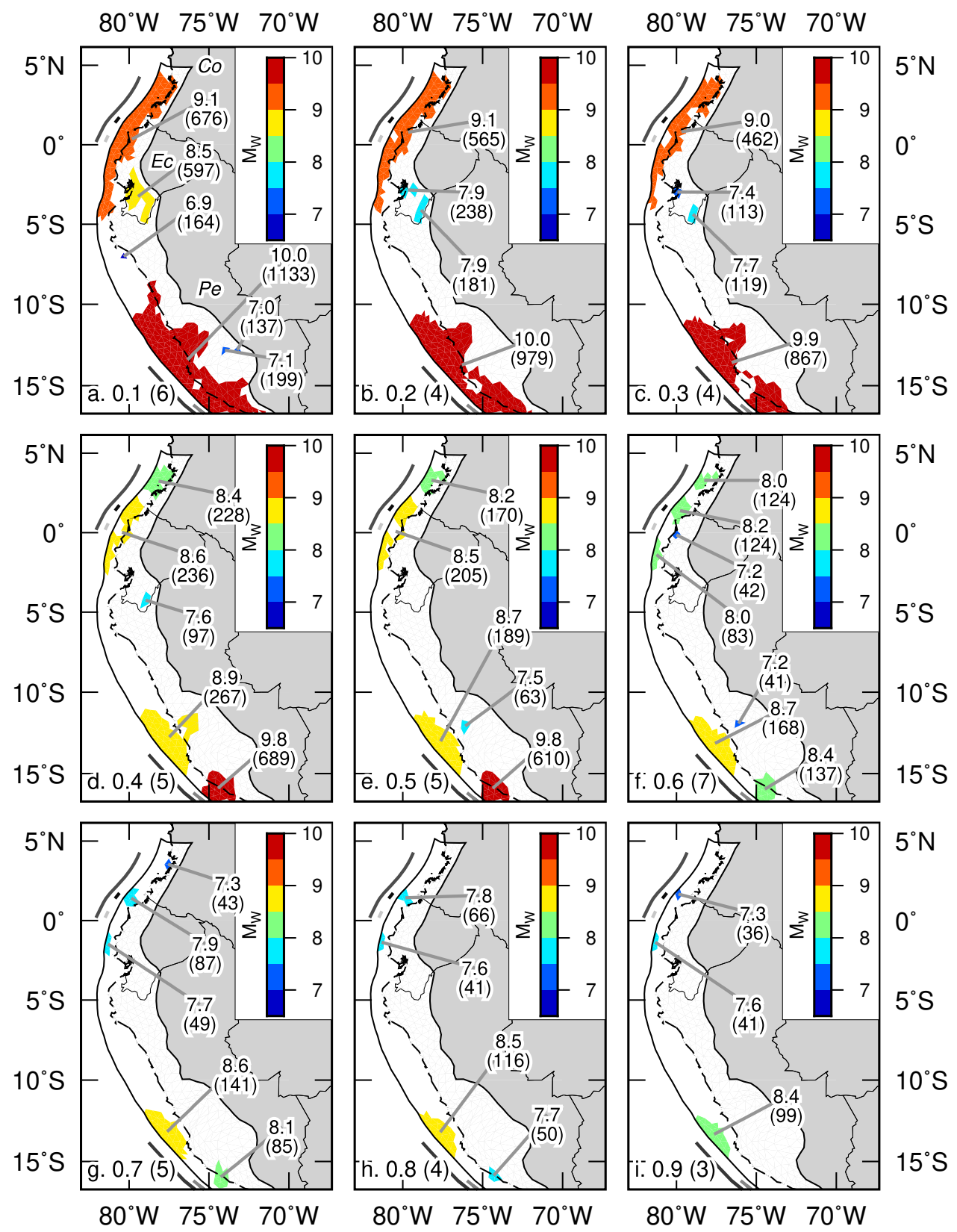

Figure 16. Proposed earthquake rupture areas based on estimated interseismic coupling on the North Andean subduction zone, with symbology and annotations as indicated in Figure 4. The southernmost, massive earthquake in panels a-e $\left(\mathrm{M}_{\mathrm{W}} \geq 9.8\right)$ continues to the south, as seen in Figure 17. Black lines on land are national boundaries, and abbreviations of country names in (a) are Co: Colombia; Ec: Ecuador; Pe: Peru. 

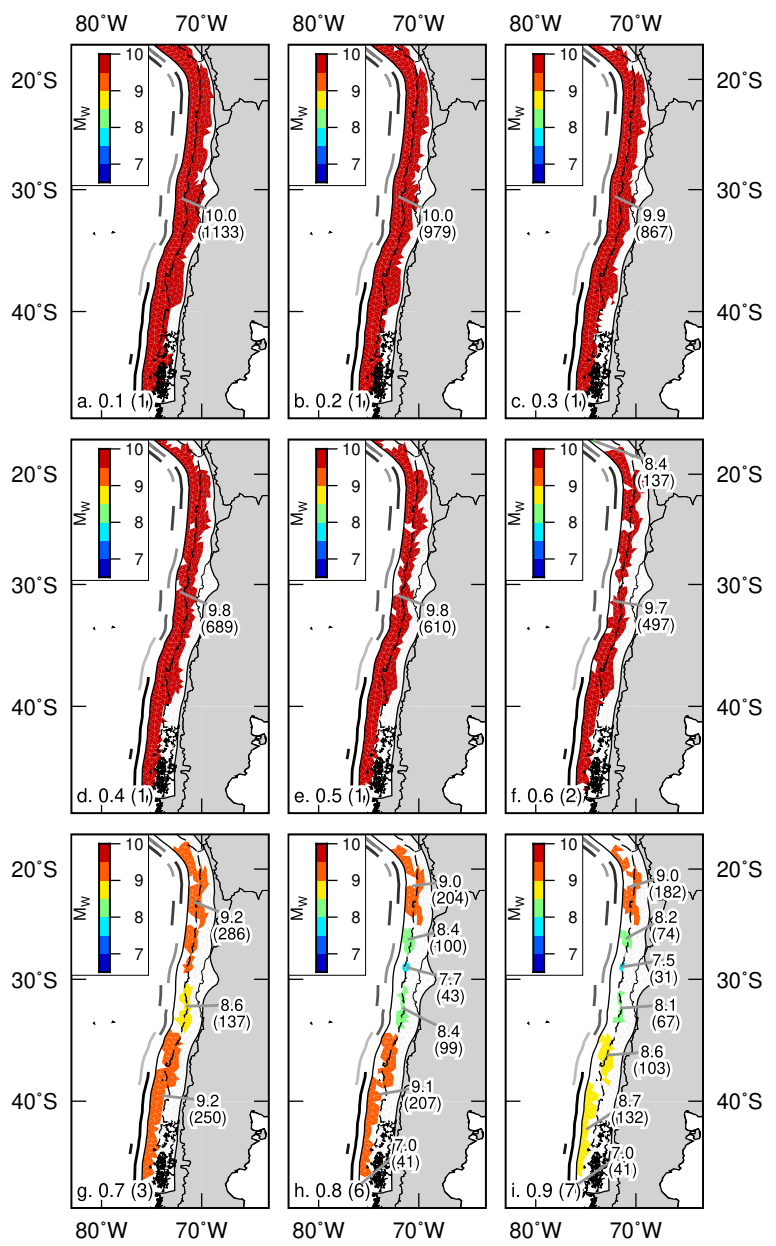

Figure 17. Proposed earthquake rupture areas based on estimated interseismic coupling on the Central Andean (Chilean) subduction zone, with symbology and annotations as indicated in Figure 4. The northernmost, massive earthquake in panels a-e $\left(\mathrm{M}_{\mathrm{W}} \geq 9.8\right)$ continues to the north, as seen in Figure 16. 

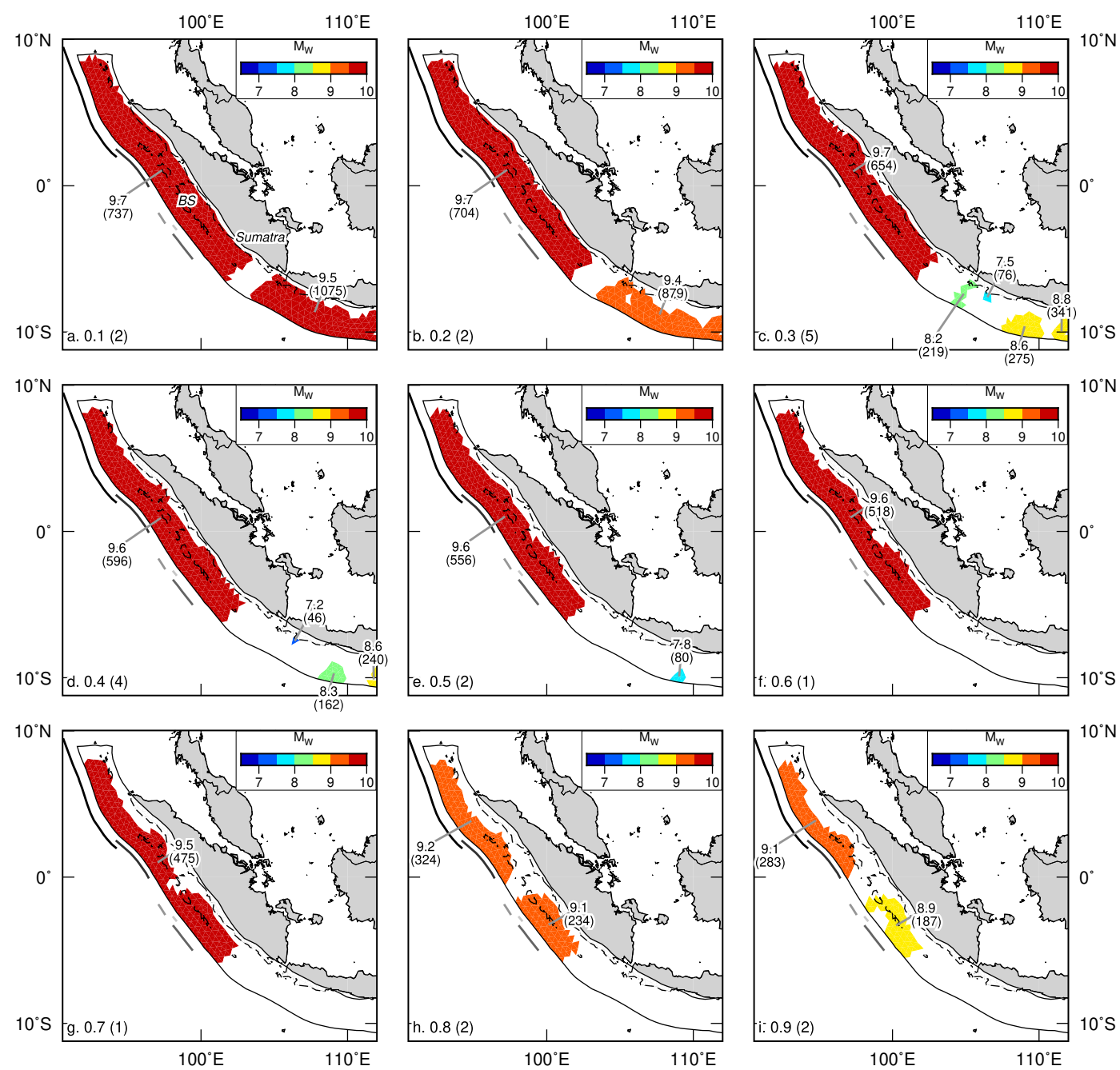

Figure 18. Proposed earthquake rupture areas based on estimated interseismic coupling on the Sumatra subduction zone, with symbology and annotations as indicated in Figure 4. Abbreviations of place name in (a) is BS: Batu Islands/Siberut. The easternmost earthquakes in panels a-d continue to the east; see Figure S9 for full Sumatra-Java subduction zone. 